\title{
Carrier Formation Dynamics in Prototypical Organic Solar Cells as Investigated by Transient Absorption Spectroscopy
}

\author{
Yutaka Moritomo, ${ }^{1,2,3}$ Kouhei Yonezawa, ${ }^{1}$ and Takeshi Yasuda ${ }^{4}$ \\ ${ }^{1}$ Graduate School of Pure and Applied Science, University of Tsukuba, Tsukuba 305-8571, Japan \\ ${ }^{2}$ Center for Integrated Research in Fundamental Science and Engineering (CiRfSE), University of Tsukuba, Tsukuba 305-8571, Japan \\ ${ }^{3}$ Tsukuba Research Center for Interdisciplinary Materials Science (TIMS), University of Tsukuba, Tsukuba 305-8571, Japan \\ ${ }^{4}$ Research Center for Functional Materials, National Institute for Materials Science (NIMS), Tsukuba 305-0047, Japan
}

Correspondence should be addressed to Yutaka Moritomo; moritomo@sakura.cc.tsukuba.ac.jp

Received 16 April 2016; Revised 12 June 2016; Accepted 23 June 2016

Academic Editor: Petr S. Sherin

Copyright (C) 2016 Yutaka Moritomo et al. This is an open access article distributed under the Creative Commons Attribution License, which permits unrestricted use, distribution, and reproduction in any medium, provided the original work is properly cited.

\begin{abstract}
Subpicosecond transient absorption spectroscopy is a powerful tool used to clarify the exciton and carrier dynamics within the organic solar cells (OSCs). In this review article, we introduce a method to determine the absolute numbers of the excitons and carriers against delay time $(t)$ only from the photoinduced absorption (PIA) and electrochemically induced absorption (EIA) spectra. Application of this method to rr-P3HT-, PTB7-, and SMDPPEH-based OSCs revealed common aspects of the carrier formation dynamics. First, the temporal evolution of the numbers of the excitons and carriers indicates that the late decay component of exciton does not contribute to the carrier formation process. This is probably because the late component has not enough excess energy to separate into the electron and hole across the donor/acceptor (D/A) interface. Secondly, the spectroscopy revealed that the exciton-to-carrier conversion process is insensitive to temperature. This observation, together with the fast carrier formation time in OSCs, is consistent with the hot exciton picture.
\end{abstract}

\section{Introduction}

1.1. Exciton-Carrier Conversion in Organic Solar Cells. Organic solar cells (OSCs) with bulk heterojunction (BHJ) [1-4] are promising energy conversion devices with high power conversion efficiency (PCE $>10 \%$ [5]), flexibility, and low-cost production process, for example, the roll-to-role process. The BHJ active layer, which consists of phaseseparated nanosize domains of the donor (D) and acceptor (A) materials, efficiently absorbs the solar energy and converts it to the electric energy. The BHJ layer is easily prepared by the spin-coating from an organic solvent and the appropriate thermal annealing. In some cases, an additive, for example, diiodooctane (DIO), in the organic solvent is effective in obtaining a fine domain structure [6]. In the actual OSCs, the active layer is sandwiched between an $\mathrm{Al}$ cathode and an indium tin oxide (ITO) transparent anode. The ITO electrode is used as an optical window.
Significant feature of the OSCs is that Frenkel-type exciton with a high binding energy is stable even at room temperature, reflecting the small dielectric constant $(\varepsilon=2-3)$ $[7,8]$. Then, the photoexcitation creates donor exciton $\left(\mathrm{D}^{*}\right)$ in the donor domain or acceptor exciton $\left(\mathrm{A}^{*}\right)$ in the acceptor domains. The photovoltaic effect is realized by the conversion process from exciton to carrier. This is in a sharp contrast with inorganic solar cells (ISCs), in which the photoexcitation directly creates free carriers in the active layer. Figure 1 schematically shows the exciton-carrier conversion process around $\mathrm{D} / \mathrm{A}$ interface. The photoirradiation directly creates excitons in the respective domains [(2) exciton formation]. The excitons migrate to the D/A interface [(3) exciton migration] and dissociate into donor hole $\left(\mathrm{D}^{+}\right)$and acceptor electron $\left(\mathrm{A}^{-}\right)$[(4) exciton dissociation]. The exciton dissociation process is the most important issue to comprehend the photovoltaic effects in OSCs. Importantly, the exciton migration distance $(\sim 10 \mathrm{~nm})$ is very short in OSCs [9]. 


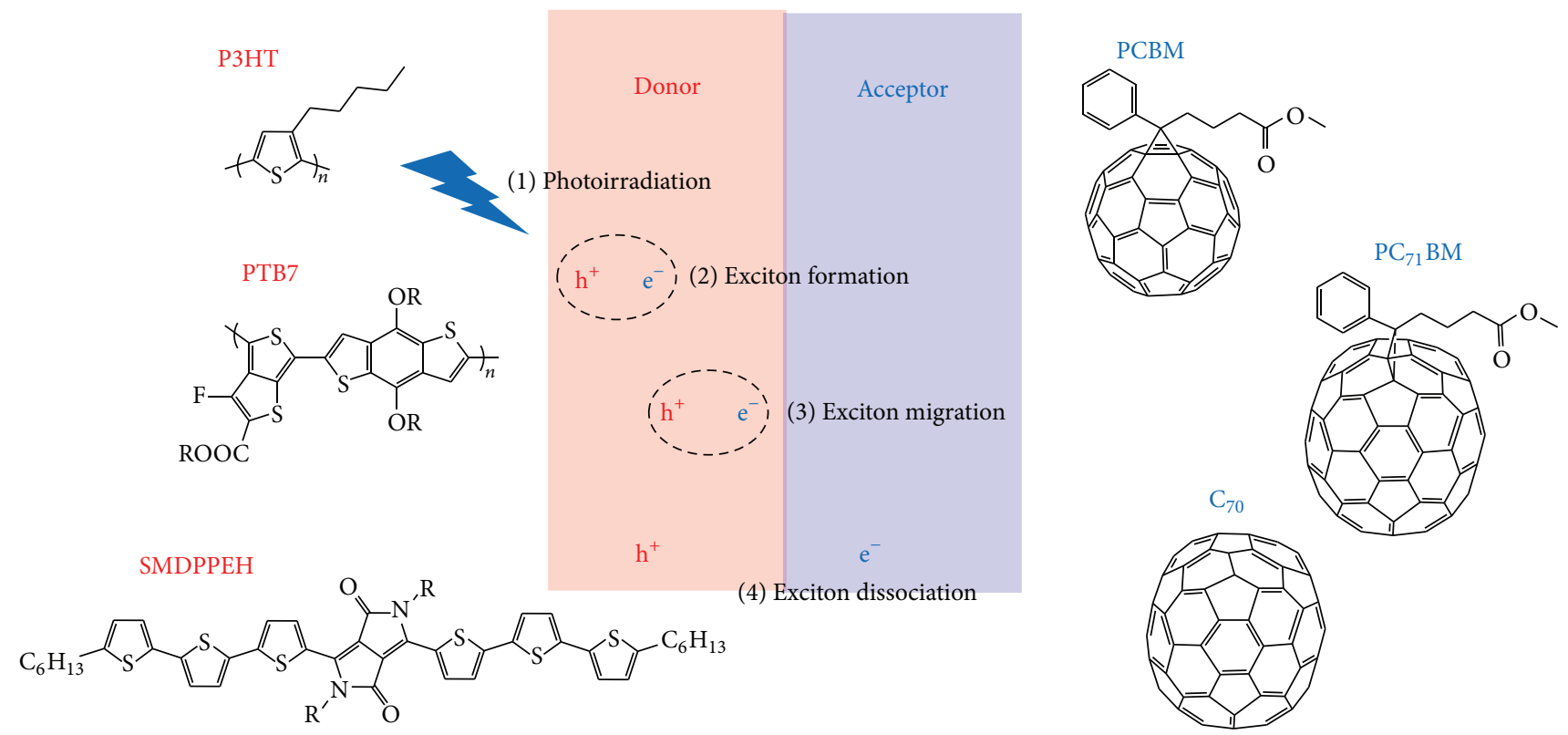

FIGURE 1: Exciton-carrier conversion process at D/A interface. Molecular structures of prototypical donors and acceptors are shown.

If the domains size is much larger than the migration distance, most of the excitons recombine before they reach the D/A interface. Therefore, the nanosize domain structure of the $\mathrm{BHJ}$ layer is indispensable for the efficient carrier formation process. After the carrier formation, $\mathrm{D}^{+}$transfers within the $\mathrm{D}$ domain to reach the anode, where the hole is collected. $\mathrm{A}^{-}$transfers within the A domain to reach the cathode, where the electron is collected.

Among the exciton-carrier conversion process, (4) exciton dissociation process is still controversial [9-19]. The Frenkel exciton in organic materials has high binding energy $(=0.2-0.5 \mathrm{eV})$ due to the electrostatic potential between them. At the D/A interfaces, the electrons will be transferred to A, provided that the energy gain overcomes the exciton binding energy. This requirement is often satisfied by an energetic offset between the donor and acceptor lowest unoccupied molecular orbitals (LUMOs). After the electron transfer, the resulting electron-hole pairs still feel electrostatic potential between them. Such a bound electron-hole state at D/A interface is known as charge-transfer (CT) state. The CT state was detected by absorption [20-24], photoluminescence [25-27], electroluminescence $[26,27]$, time-resolved/pulsed electron paramagnetic resonance [28-31], and transient absorption spectroscopy [32-41]. Importantly, the free carrier formation from the CT state is very fast, as demonstrated by transient absorption spectroscopies [32-41]. Hwang et al. [32] reported that free carriers were generated from the CT state within a few picoseconds in P3HT/PCBM blend film. Using sub-20 fs pump-probe spectroscopy, Grancini et al. [41] observed the generation of free carries within $50 \mathrm{fs}$ in the PCPDTBT/PCBM blend film.

There exists a long-lasting debate whether the carriers are generated from the hot CT or relaxed CT state. In the hot CT picture, the excess energy helps to dissociate the CT states directly to the free carriers before they reach the relaxed CT states [42]. In this picture, the primary kinetic competition is between the energy relaxation and the dissociation of the hot CT state. The energy relaxation process is usually several hundred femtoseconds [43]. However, several experimental results on the internal quantum efficiency (IQE) [44, 45] are against the hot CT picture. For example, Vandewal et al. [45] reported that IQE is irrespective of the excitation energy in the MEH-PPV/PCBM OSC. This data strongly indicates that free carrier generation is exclusively from the relaxed $\mathrm{CT}$ state rather than from the hot CT state. In this situation, a new spectroscopic approach is desired to deepen the understanding of the exciton dissociation.

1.2. Spectroscopic Determination of Absolute Numbers of Photogenerated Species. The transient absorption spectroscopy is one of the powerful tools used to clarify the dynamics of the exciton, CT state, and carrier. The spectroscopy has been applied to the OSCs with BHJ active layers [42, 43, 46-61]. Figure 2 shows schematic diagram of the transient absorption spectroscopy. The irradiation of the pump light pulse creates $\mathrm{D}^{*}, \mathrm{~A}^{*}, \mathrm{D}^{+}$, and $\mathrm{A}^{-}$. These species cause the photoinduced absorption (PIA) below the absorption edge, as shown in the right panels of Figure 2. This PIA is monitored by the probe light pulse against delay time $(t)$.

Here, let us introduce a method to determine the absolute numbers of the excitons and carriers against $t$ only from the photoinduced absorption (PIA) and electrochemically induced absorption (EIA) spectra. In the latter spectroscopy, the electrochemically doped carrier causes a characteristic EIA in the infrared region. In this method, we only consider the photogenerated exciton and carrier and eliminate material dependent assumptions on the spectral interpretation as much as possible. Then, PIA $\left(\phi_{\exp }\right)$ is decomposed into the respective PIA components, that is, $\phi_{\mathrm{D}^{*}}$ (donor exciton), $\phi_{\mathrm{A}^{*}}$ 


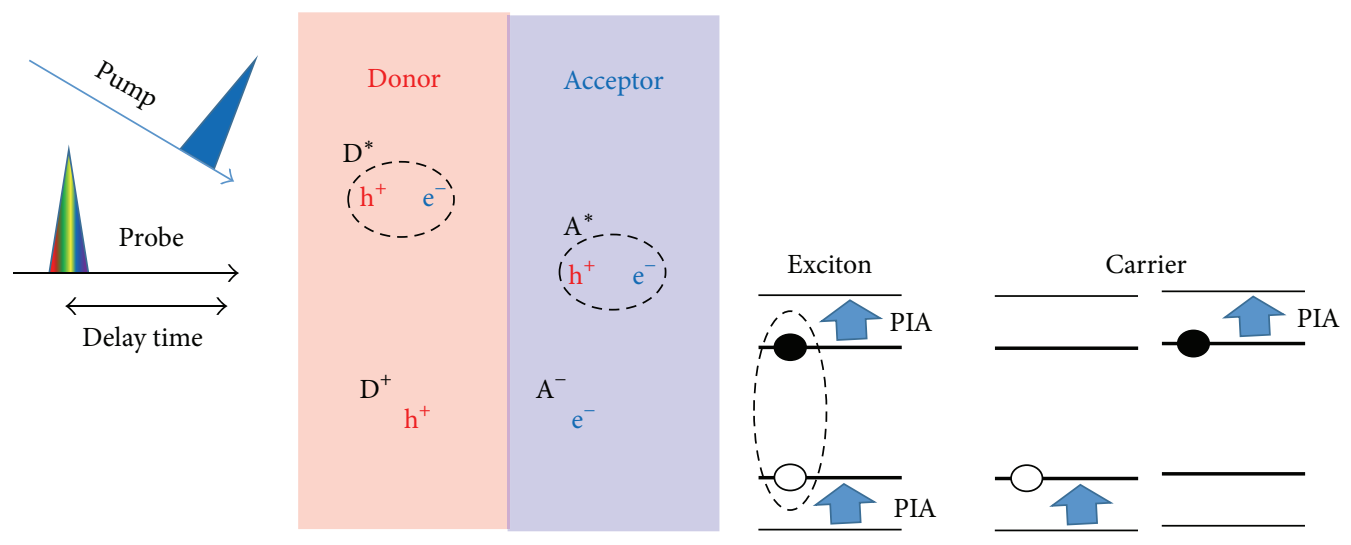

FIGURE 2: Schematic diagram of the transient absorption spectroscopy. Photoexcitation generates donor exciton $\left(\mathrm{D}^{*}\right)$, acceptor exciton $\left(\mathrm{A}^{*}\right)$, donor hole $\left(\mathrm{D}^{+}\right)$, and acceptor electron $\left(\mathrm{A}^{-}\right)$. Right panel shows energy level diagram for exciton and carrier together with photoinduced absorption (PIA).

(acceptor exciton), and $\phi_{\mathrm{D}^{+} \mathrm{A}^{-}}$(carriers). $\phi_{\mathrm{D}^{*}}\left(\phi_{\mathrm{A}^{*}}\right)$ should be the PIA of the donor (acceptor) neat films at the early stage after photoexcitation. $\phi_{\mathrm{D}^{+} \mathrm{A}^{-}}$should be the PIA of the blend film at the late stage, where photogenerated excitons completely disappear. We note that $\phi_{\mathrm{D}^{+} \mathrm{A}^{-}}$is dominated by the PIA due to $\mathrm{D}^{+}$, because the profile of the late component significantly depends on the donor material and resembles that of the EIA of the donor neat film. This suggests that $\phi_{\mathrm{A}^{-}}$ is much weaker than $\phi_{\mathrm{D}^{+}}$. The CT state inevitably coexists with excitons because its lifetime $(<50 \mathrm{fs}[41])$ is very short. Therefore, it is impossible to determine the PIA $\left(\phi_{\mathrm{CT}}\right)$ due to the CT state without material dependent assumptions. By the spectral decomposition, the relative numbers of the excitons $\left(n_{\mathrm{D}^{*}}\right.$ and $\left.n_{\mathrm{A}^{*}}\right)$ and carrier $\left[n_{\mathrm{D}^{+}}\left(=n_{\mathrm{A}^{-}}\right)\right]$can be determined against $t$. Here, we define $N_{\text {photon }}, N_{\text {exciton }}$, and $N_{\text {carrier }}$ as the numbers of absorbed photons, excitons, and carriers, respectively. $\Delta_{\text {exciton }} / N_{\text {photon }}\left(\Delta_{\text {exciton }}\right.$ is the exciton components of spectral change) is evaluated from the PIA of the blend film. $\Delta_{\text {exciton }} / N_{\text {exciton }}$ is evaluated from the PIA of the neat film, with assuming that one absorbed photon creates one exciton. Then, the absolute number $\left(n_{\text {exciton }}\right)$ of the photogenerated excitons per an absorbed photon is expressed as

$$
n_{\text {exciton }}=\frac{\left(\Delta_{\text {exciton }} / N_{\text {photon }}\right)}{\left(\Delta_{\text {exciton }} / N_{\text {exciton }}\right)} .
$$

Similarly, $\Delta_{\text {carrier }} / N_{\text {photon }}\left(\Delta_{\text {carrier }}\right.$ is the carrier components of spectral change) is evaluated from the PIA of the blend film. On the other hand, $\Delta_{\text {carrier }} / N_{\text {carrier }}$ is evaluated from the EIA of the neat film. Then, the absolute number $\left(n_{\text {carrier }}\right)$ of the photogenerated carriers per an absorbed photon is expressed as

$$
n_{\text {carrier }}=\frac{\left(\Delta_{\text {carrier }} / N_{\text {photon }}\right)}{\left(\Delta_{\text {carrier }} / N_{\text {carrier }}\right)} .
$$

The drawback of this method is that it does not explicitly include the CT state, which is believed to play an essential role in the carrier formation process. Nevertheless, the simple model, which excludes material dependent assumptions, has two advantages over the conventional complicated models. First, the model enables us to determine the absolute numbers of the excitons (carriers) against $t$ only from the spectroscopic data. Secondly, the model is applicable to even unknown D/A systems, because we can experimentally determine $\phi_{\mathrm{D}^{*}}, \phi_{\mathrm{A}^{*}}$, and $\phi_{\mathrm{D}^{+} \mathrm{A}^{-}}$without any material dependent assumptions.

We note that the temperature effect on the carrier formation dynamics gives us a clue on the carrier formation mechanism. For example, Yonezawa et al. [60] reported that the carrier formation efficiency $\left(\Phi_{\mathrm{CF}}\right)$, which is defined as the number of the photoinduced carriers per an absorbed photon, is nearly insensitive to temperature in several OSCs. This suggests that the exciton dissociation is treated by quantum-mechanical approach [62-67] and not by the socalled Marcus picture [68]. In the former picture, the exciton dissociation is quantum-mechanically treated by the timeevolution of a wave function. In the latter picture, the charge separation is classically treated by the energy shift induced by displacement of the surrounding molecules.

1.3. Donor Polymers and Small Molecules for OSC. Historically, extensive spectroscopic investigations [32-43, 46-51] have been carried out on the charge formation dynamics in regioregular poly(3-hexylthiophene) (rr-P3HT)/[6,6]-phenyl $\mathrm{C}_{61}$-butyric acid methyl ester (PCBM) blend film, due to its reproducible power conservation efficiency (PCE > 5\% [69-71]). In particular, the regioregularity of P3HT and the annealing procedure have significant effects on the carrier formation dynamics of P3HT/PCBM blend film. The crosssectional transmission electron microscopy (TEM) of rr$\mathrm{P} 3 \mathrm{HT} / \mathrm{PCBM}$ blend film shows characteristic pathway for carrier transport through the film thickness. The length scale of the phase separation was $24 \mathrm{~nm}$ [72]. The recent development of the low-band gap donor polymers further increased PCE beyond 5\%, which motivated intensive spectroscopic investigation of the low-band gap donor polymers [56-64]. In particular, Yu and coworkers $[73,74]$ have developed a series of donor polymers based on alternating ester-substituted 


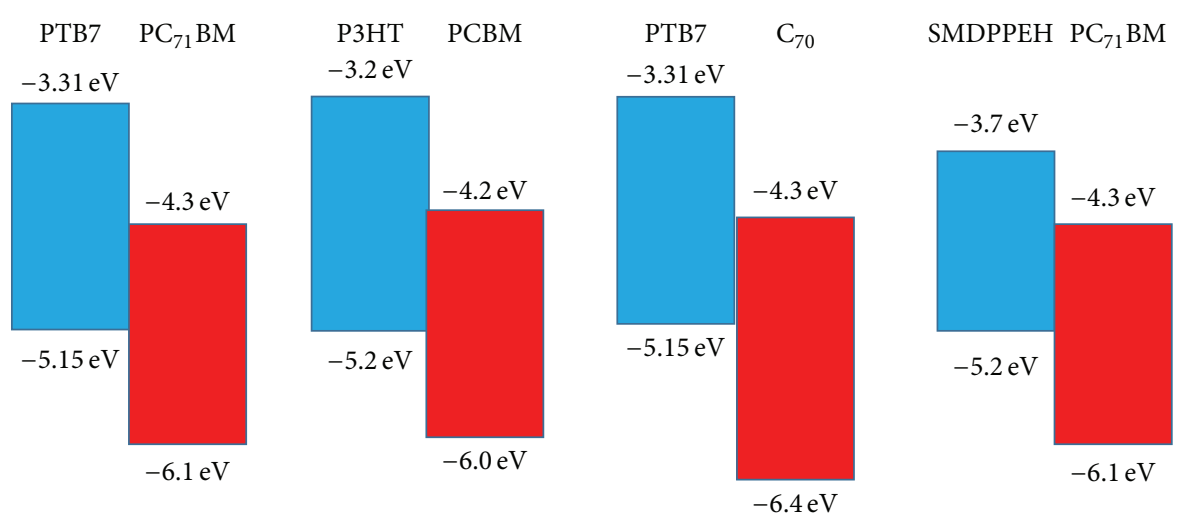

FIgURE 3: Energy level diagrams of various D/A interface.

thieno[3,4-b]thiophene and benzodithiophene units (PTBn: $n=1-7)$. The poly[[4,8-bis [(2-ethylhexyl)oxy] benzo [1,2$\mathrm{b}: 4,5-\mathrm{b}^{\prime}$ ] dithiophene-2,6-diyl] [3-fluoro-2-[(2-ethylhexyl) carbonyl] thieno [3,4-b] thiophenediyl]] (PTB7)/[6,6]-phenyl $\mathrm{C}_{71}$-butyric acid methyl ester ( $\left.\mathrm{PC}_{71} \mathrm{BM}\right)$ OSC shows a high PCE ( 9\% [75]). The AFM images [76] of the PCE-optimized PTB7/PC ${ }_{71}$ BM blend films show fiber-like structures (10$50 \mathrm{~nm}$ wide and 200-400 $\mathrm{nm}$ long), which are ascribed to the donor- or acceptor-rich domains.

The domain structure of the $\mathrm{BHJ}$ layer is complicated and its relation to the PCE value is still controversial. By means of the scanning transmission X-ray microscopy (STXM), Collins et al. [77] investigated the domain structure of $\mathrm{PTB} 7 / \mathrm{PC}_{71} \mathrm{BM}$ blend film prepared without additive. They found that the PTB7-rich domain shows considerable fullerene mixing. By means of atomic force microscopy (AFM) coupled with plasma-ashing technique, Hedley et al. [76] observed a substructure of $\sim 10 \mathrm{~nm}$ inside the fullerene domain $(\sim 100 \mathrm{~nm})$ of the PTB7/PC 71 BM blend film prepared without additive. Such a complexity of the domain structure of the $\mathrm{BHJ}$ layer may prevent a true understanding of the carrier formation dynamics. In this sense, a planar heterojunction (HJ) OSC with well-defined D/A interface is suitable for detailed investigation on the carrier formation and recombination dynamics [78-80]. For example, Moritomo et al. [80] revealed carrier density effect on the carrier recombination process in $\mathrm{PTB} 7 / \mathrm{C}_{70} \mathrm{HJ}$ solar cell.

Another candidates for the donor materials are the small molecules, because they are easy to synthesize and purify. This is in sharp contrast with the polymer donors, which suffer from bad synthetic reproducibility and difficult purification procedures [81, 82]. Among small molecular donors, diketopyrrolopyrrole (DPP) pigments were developed in the early 1970s and have been widely used in inks, paints, and plastics [83]. Recently, Nguyen's group developed an oligothiophene-DPP molecule with ethylhexyl substituents terthiophen-5-yl)-pyrrolo[3,4-c]pyrrolo-1,4-dione] (SMDP$\mathrm{PEH})[83,84]$. The SMDPPE-based OSC shows a high PCE ( 3\% [85]) with $\mathrm{PC}_{71} \mathrm{BM}$ among the small molecule-based OSCs. The AFM images [85] of the PCE-optimized SMDP$\mathrm{PEH} / \mathrm{PC}_{71} \mathrm{BM}$ blend films show fiber-like ( $20 \mathrm{~nm}$ wide and $\sim 50 \mathrm{~nm}$ long) and overshaped structures, which are ascribed to the donor- and acceptor-rich domains, respectively.

In this review article, we introduce a method to determine the absolute numbers of the excitons and carriers against $t$ only from the PIA and EIA spectra. The method was applied

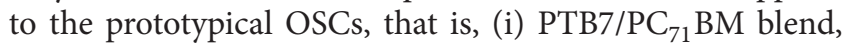
(ii) rr-P3HT/PCBM blend, (iii) $\mathrm{PTB} / / \mathrm{C}_{70}$ bilayer, and (iv) SMDPPEH/PC ${ }_{71} \mathrm{BM}$ blend films. Figure 3 shows energy level diagram for respective D/A interfaces. Quantitative analyses clarified important aspects of the carrier formation dynamics in the OSCs. First, the late decay component of exciton does not contribute to the carrier formation process, as observed in (i) $\mathrm{PTB} / \mathrm{PC}_{71} \mathrm{BM}$ blend, (ii) rr-P3HT/PCBM blend, (iii) $\mathrm{PTB} / / \mathrm{C}_{70}$ bilayer, and (iv) SMDPPEH/PC ${ }_{71} \mathrm{BM}$ blend films. This is probably because the late component has not enough excess energy to separate into electron and hole at D/A interface. Secondly, the exciton-carrier conversion process is insensitive to temperature, as observed in (iii) PTB7/C 70 bilayer and (iv) SMDPPEH/PC ${ }_{71} \mathrm{BM}$ blend films. This observation, together with the fast carrier formation time in OSCs, is consistent with the hot exciton picture.

\section{Experimental Technique}

2.1. Transient Absorption Spectroscopy. Figure 4 shows a prototypical setup for the transient absorption spectroscopy. Second harmonics $(=400 \mathrm{~nm})$ of the regenerative amplified Ti:sapphire laser are usually used as the pump pulse. In some cases, the wavelength of the pump pulse is converted with use of an optical parametric amplifier (OPA). A white pulse, which is generated by self-phase modulation in a sapphire plate, is used as the probe pulse. The delay stage controls the delay time $(t)$ between the pump and probe pulse. The spectra of the transmitted probe pulse are analyzed with a multichannel detector attached to a spectrometer. The differential absorption spectra $(\Delta \mathrm{OD})$ are defined as $\Delta \mathrm{OD}=$ $-\ln \left(I_{\text {on }} / I_{\text {off }}\right)$, where $I_{\text {on }}$ and $I_{\text {off }}$ are the transmitted light intensity with and without pump excitation, respectively. The photogenerated exciton and carrier cause characteristic PIA in the infrared region. 


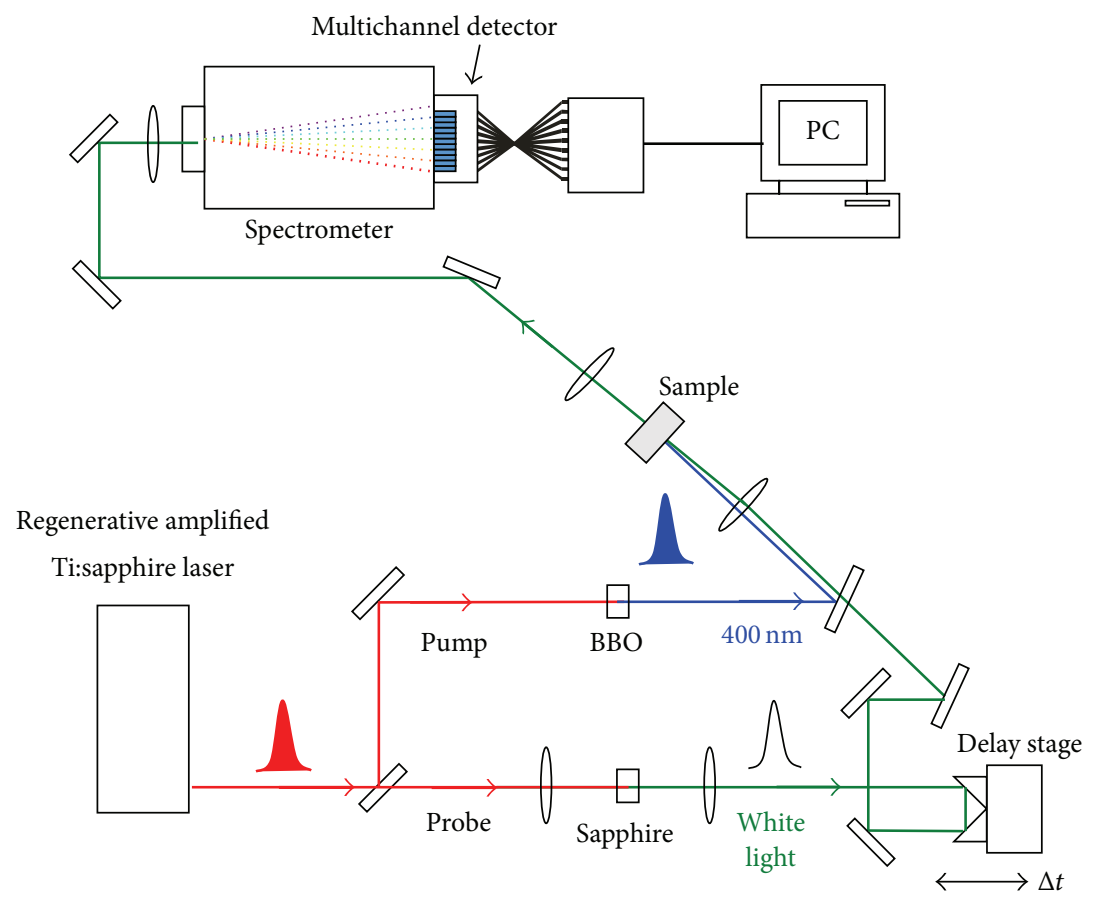

FIGURE 4: Schematic illustration of the experimental setup for transient absorption spectroscopy.

2.2. Electrochemical Differential Absorption Spectroscopy. The electrochemical differential absorption spectra $\left(\Delta \mathrm{OD}_{\mathrm{EC}}\right)[61]$ are defined as $\Delta \mathrm{OD}_{\mathrm{EC}}=-\ln \left(I_{\text {doped }} / I_{\text {non }}\right)$, where $I_{\text {doped }}$ and $I_{\text {non }}$ are the transmitted spectra of hole-doped and nondoped films, respectively. The electrochemically doped carrier causes a characteristic EIA in the infrared region. The doped carrier density $\left(n_{\mathrm{D}^{+}}\right)$is evaluated from the current density and doping time. The electrochemical carrier-doping was usually performed in two-pole electrochemical cell with a pair of quartz windows. The electric current is parallel to the light path. The cathode and anode are the donor neat film and a small piece of Li metal. The electrolyte is usually propylene carbonate (PC) solution containing $1 \mathrm{~mol} / \mathrm{LiClO}_{4}$.

\section{PTB7/PC ${ }_{71}$ BM Blend Film: A Prototypical Example}

3.1. Decomposition of the PIA Spectra. First of all, let us demonstrate how to decompose the PIA into the respective components, that is, $\phi_{\mathrm{D}^{+} \mathrm{A}^{-}}, \phi_{\mathrm{A}^{*}}$, and $\phi_{\mathrm{D}^{*}}$. Figure 5(a) shows $\Delta$ OD spectra of the PTB7/PC ${ }_{71}$ BM blend film. The PIA spectra in the late stage ( $>1 \mathrm{ps}$ ) show broad PIA around $1150 \mathrm{~nm}$. The PIA is originated from the photoinduced carriers $\left(\mathrm{D}^{+}\right)$of PTB7 [57-60]. Actually, the spectral profile is similar to that of the electrochemical differential absorption spectra of the PTB7 neat film (vide infra). Therefore, the PIA in the late stage can be used as $\phi_{\mathrm{D}^{+} \mathrm{A}^{-}}$. We note that the photoexcitation of the $\mathrm{BHJ}$ layer creates the excitons, not the carriers. Therefore, the PIA in the early state $(<1 \mathrm{ps})$ is overlapped by PIA due to $n_{\mathrm{D}^{*}}$ and $n_{\mathrm{A}^{*}}$. Figure $5(\mathrm{~b})$ shows $\triangle \mathrm{OD}$ spectra of $\mathrm{PC}_{71} \mathrm{BM}$ neat film. The PIA due to $A^{*}$ is very flat and the spectral shape is independent of $t$. Then, the PIA can be used as $\phi_{\mathrm{A}^{*}}$.
Figure 5(c) shows $\triangle$ OD spectra of PTB7 neat film. PIA due to $\mathrm{D}^{*}$ shows broad peak around $1200 \mathrm{~nm}$ and the spectral shape is nearly independent of $t(<10 \mathrm{ps})$. Then, the PIA ( $<10 \mathrm{ps})$ can be used as $\phi_{\mathrm{D}^{*}}$.

Now, we can decompose $\phi_{\exp }$ of $\mathrm{PTB} 7 / \mathrm{PC}_{71} \mathrm{BM}$ blend film into $\phi_{\mathrm{D}^{+} \mathrm{A}^{-}}, \phi_{\mathrm{A}^{*}}$, and $\phi_{\mathrm{D}^{*}}$. The spectral weights of the respective components were determined so that they minimize the following trial function: $F\left(C_{\mathrm{D}^{+} \mathrm{A}^{-}}, C_{\mathrm{A}^{*}}, C_{\mathrm{D}^{*}}\right)=$ $\sum_{i}\left[C_{\mathrm{D}^{+} \mathrm{A}^{-}} \phi_{\mathrm{D}^{+} \mathrm{A}^{-}}\left(\lambda_{i}\right)+C_{\mathrm{A}^{*}} \phi_{\mathrm{A}^{*}}\left(\lambda_{i}\right)+C_{\mathrm{D}^{*}} \phi_{\mathrm{D}^{*}}\left(\lambda_{i}\right)-\phi_{\exp }\left(\lambda_{i}\right)\right]^{2}$. The PIA of the blend film at 3 ps was used as $\phi_{\mathrm{D}^{+} \mathrm{A}^{-}}$. The PIA of $\mathrm{PC}_{71} \mathrm{BM}$ neat film at $1 \mathrm{ps}$ was used as $\phi_{\mathrm{A}^{*}}$. The PIA of PTB7 neat film at $1 \mathrm{ps}$ was used as $\phi_{\mathrm{D}^{*}}$. Figure 6 shows examples of the decomposition of the PIA spectra into $\phi_{\mathrm{D}^{+} \mathrm{A}^{-}}, \phi_{\mathrm{A}^{*}}$, and $\phi_{\mathrm{D}^{*}}$. Strictly speaking, the cross sections for the respective species may differ between the neat and blend films. The difference is considered to be negligible because the PIA is measured in the infrared region below the optical gap.

3.2. Absolute Numbers of the Elementary Excitations. In order to spectroscopically evaluate $n_{\mathrm{D}^{+}}, n_{\mathrm{D}^{*}}$, and $n_{\mathrm{A}^{*}}$ per an absorbed photon, we need the absolute intensity of the PIA per unit densities of $\mathrm{D}^{+}, \mathrm{D}^{*}$, and $\mathrm{A}^{*}$. The absolute intensity of the PIA due to $\mathrm{D}^{+}$is easily evaluated by the electrochemical differential absorption spectroscopy [61]. Figure 6 shows examples of the electrochemical differential spectra $\left(\Delta \mathrm{OD}_{\mathrm{EC}}\right)$. The shoulder-like structure in $\Delta \mathrm{OD}_{\mathrm{EC}}$ spectrum [Figure 7(a)] of rr-P3HT neat film is analogous to the PIA spectrum of rr-P3HT/PCBM blend film. Similarly, the broad peak structure in $\triangle \mathrm{OD}_{\mathrm{EC}}$ spectrum [Figure $7(\mathrm{~b})$ ] of the PTB7 neat film is analogous to the PIA spectrum of the $\mathrm{PTB} / \mathrm{PC}_{71} \mathrm{BM}$ blend film. The absolute intensity of the PIA can be evaluated from $\triangle \mathrm{OD}_{\mathrm{EC}}$ spectrum of PTB7 neat film 

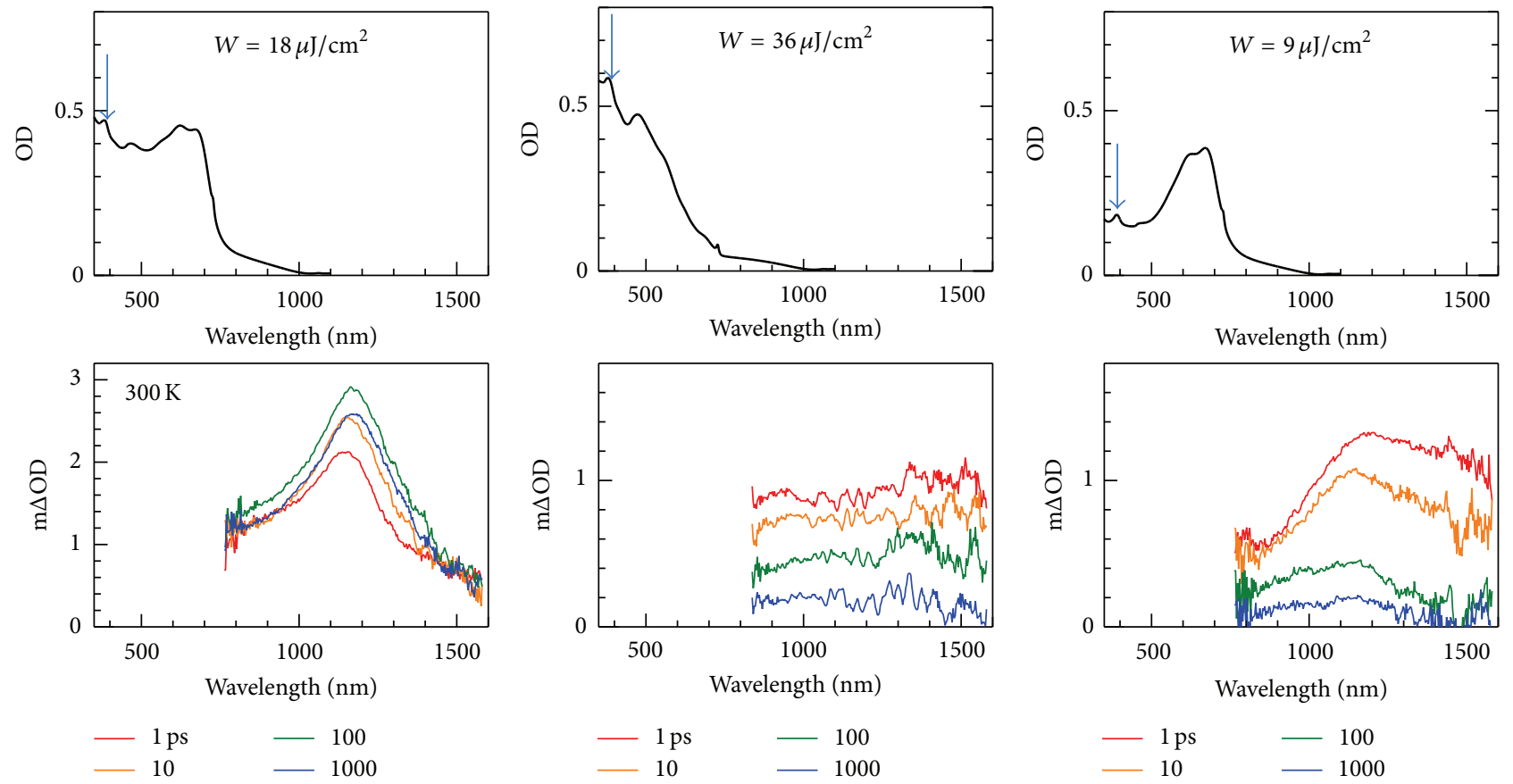

(b)

(c)

Figure 5: Differential absorption $\left(\triangle \mathrm{OD}\right.$ ) spectra of (a) PTB7/PC $\mathrm{P}_{71} \mathrm{BM}$ blend, (b) $\mathrm{PC}_{71} \mathrm{BM}$ neat, and (c) PTB7 neat films at $300 \mathrm{~K}$. Top panels show optical density (OD) of the films at $300 \mathrm{~K}$. Downward arrows represent the wavelength of the pump pulse. The data were replotted from [54].

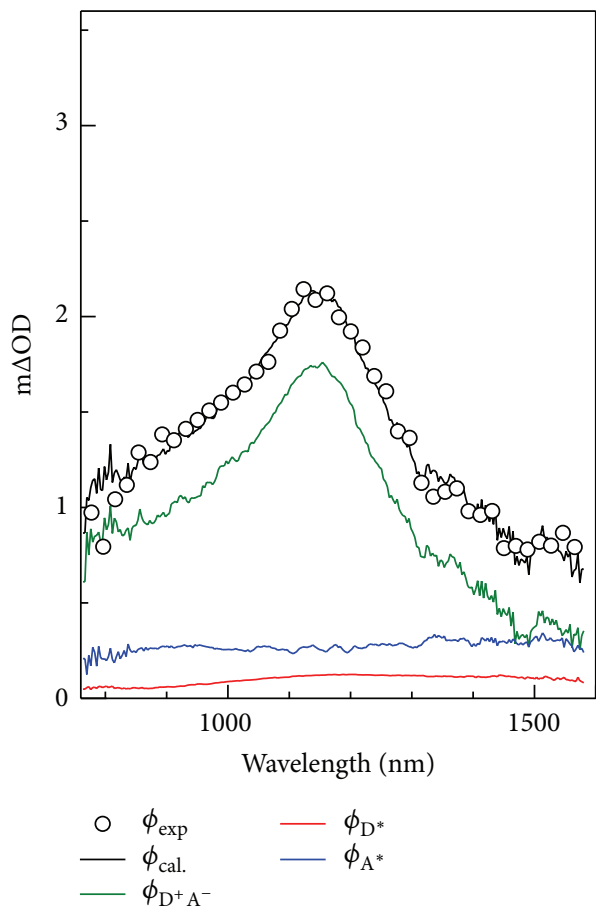

(a)

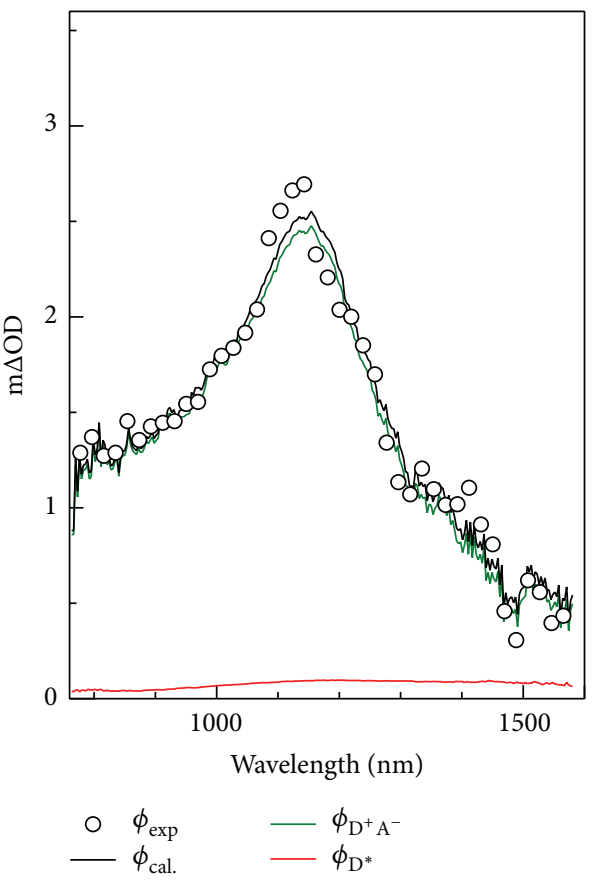

(b)

Figure 6: $\triangle \mathrm{OD}$ spectra of PTB7/PC 71 BM blend film at (a) $0.3 \mathrm{ps}$ and (b) $2.7 \mathrm{ps}$ at $300 \mathrm{~K}$. Solid curves are results of the decomposition into $\phi_{\mathrm{D}^{+} \mathrm{A}^{-}}, \phi_{\mathrm{A}^{*}}$, and $\phi_{\mathrm{D}^{*}}$. 


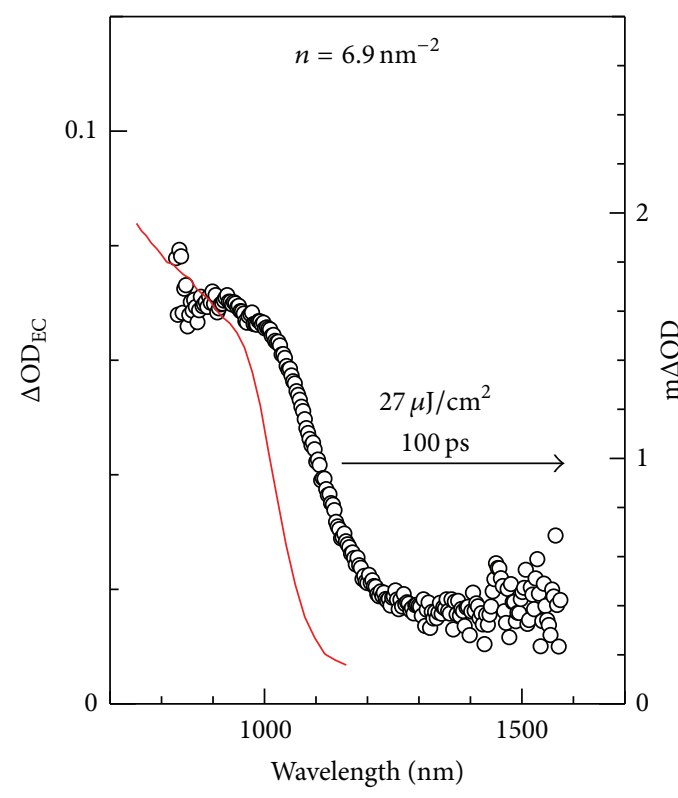

(a)

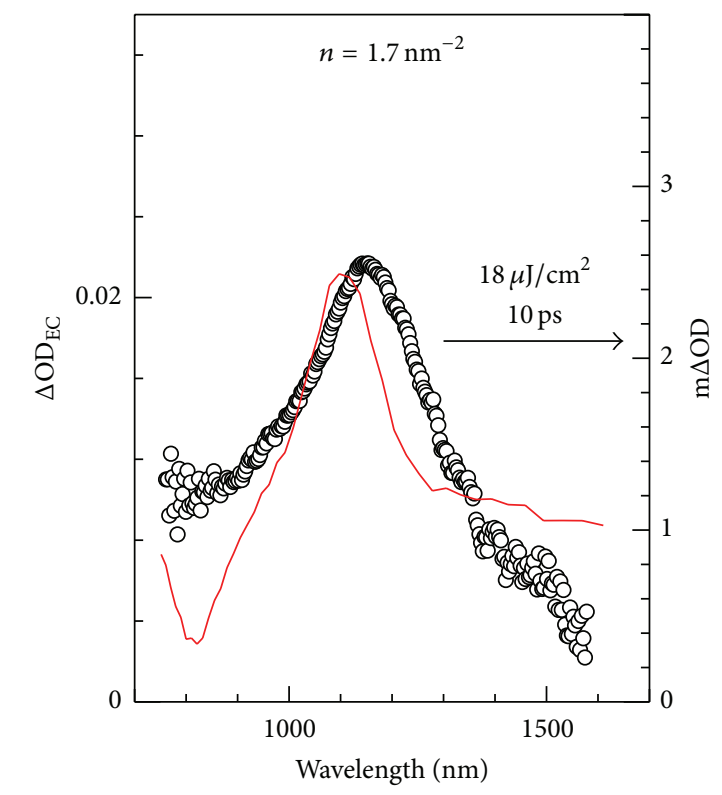

(b)

Figure 7: Electrochemical differential $\left(\Delta \mathrm{OD}_{\mathrm{EC}}\right)$ spectra of neat (a) rr-P3HT and (b) PTB7 films. Open circles represent $\Delta \mathrm{OD}$ spectra of (a) rr-P3HT/PCBM and (b) PTB7/PC ${ }_{71}$ BM blend films. The data were replotted from [61].

with considering the electrochemically doped carrier number per unit area. Concerning $\mathrm{D}^{*}\left(\mathrm{~A}^{*}\right)$, it is reasonable to assume that one absorbed photon creates one $\mathrm{D}^{*}\left(\mathrm{~A}^{*}\right)$ in the donor (acceptor) neat film. Then, the absolute intensity was evaluated from $\triangle \mathrm{OD}$ spectrum of PTB7 $\left(\mathrm{PC}_{71} \mathrm{BM}\right)$ neat film with considering the absorption photon number per unit area.

3.3. Carrier Formation Dynamics. Figure 8 shows $n_{\mathrm{D}^{+}}, n_{\mathrm{D}^{*}}$, and $n_{\mathrm{A}^{*}}$ per an absorbed photon in PTB7/PC $\mathrm{P}_{71} \mathrm{BM}$ blend film against $t$. The solid curves are results of least-squares fittings with exponential functions. The carrier formation time $\left(\tau_{\mathrm{D}^{+}}\right.$ $=0.3 \mathrm{ps}$ ) is very fast. Fast $\tau_{\mathrm{D}^{+}}$is ascribed to the molecular mixing [77] as well as the nanosize domain structure [76] of the BHJ. Here, we emphasized that the excitation pulse at $400 \mathrm{mn}$ was dominantly absorbed by the acceptor fullerene, not by PTB7 [see upper panels of Figures 5(a) and 5(b)]. Consequently, the photoexcitation only creates $A^{*}$. It is interesting that exciton decay time $\left(\tau_{\mathrm{A}^{*}}=1.5 \mathrm{ps}\right)$ is much slower than $\tau_{\mathrm{D}^{+}}$. This indicates that the late decay component of $\mathrm{A}^{*}$ does not contribute to the carrier formation process.

There are two possibilities to why the late component of $\mathrm{A}^{*}$ does not dissociate. One possibility is that the exciton recombines before it reaches $\mathrm{D} / \mathrm{A}$ interface. This scenario, however, cannot explain fast $\tau_{\mathrm{A}^{*}}(=1.5 \mathrm{ps})$ of $\mathrm{A}^{*}$, as follows. Without D/A interface, the decay channel of exciton is (i) radiative recombination, (ii) triplet exciton formation, and (iii) exciton-exciton annihilation. Among them, the former two channels cannot explain fast $\tau_{\mathrm{A}^{*}}(=1.5 \mathrm{ps})$ of $\mathrm{A}^{*}$, because typical times for these channels are on the order of nanoseconds. On the other hands, $\tau_{\mathrm{A}^{*}}$ of neat $\mathrm{PC}_{71} \mathrm{BM}$ film is 120 ps [54], which can be ascribed to the (iii) excitonexciton annihilation in bulk. The value, however, is much longer than the observed $\tau_{\mathrm{A}^{*}}(=1.5 \mathrm{ps})$. Another possibility is that the exciton dissociation efficiency decreases with $t$. This is plausible because the excess energy of $\mathrm{A}^{*}$ should decrease with $t$. Then, late $\mathrm{A}^{*}$ component has not enough excess energy to separate into electron and hole across D/A interface. Fast $\tau_{\mathrm{A}^{*}}$ in the blend film is probably ascribed to the extra recombination process at D/A interface, such as quench on free carrier or some structural defect. By means of a timeevolution simulation of a wave packet, Iizuka and Nakayama [67] theoretically investigated exciton dissociation at D/A interface. They demonstrated that the dissociation probability increases for the hot excitons compared with the groundstate exciton owing to their small binding energies and large diameters. The present method does not explicitly include the CT state, which is believed to play an essential role on the carrier formation process. Nevertheless, if $\phi_{\mathrm{CT}}$ is nearly the same as $\phi_{\mathrm{D}^{+} \mathrm{A}^{-}}$, the experimental results suggest that excess energy is needed even for the formation of the CT state.

\section{P3HT/PCBM Blend Film: Classical but Complicated System}

4.1. PIA Spectra and Analyses. As mentioned in the introduction, there already exists extensive spectroscopic investigation on rr-P3HT/PCBM blend film in literatures [3243, 46-51]. Nevertheless, we reanalyzed the PIA spectra of rrP3HT/PCBM blend film [46] and tried to determine $n_{\mathrm{D}^{+}}, n_{\mathrm{D}^{*}}$, and $n_{\mathrm{A}^{*}}$ per an absorbed photon against $t$. Systematic analyses of the PIA spectra in the different BHJ systems may reveal common aspects of the carrier formation dynamics in the OSCs.

Figure 9(a) shows $\triangle \mathrm{OD}$ spectra of $\mathrm{rr}-\mathrm{P} 3 \mathrm{HT} / \mathrm{PCBM}$ blend film. The PIA spectra in the late stage (>10 ps) show 


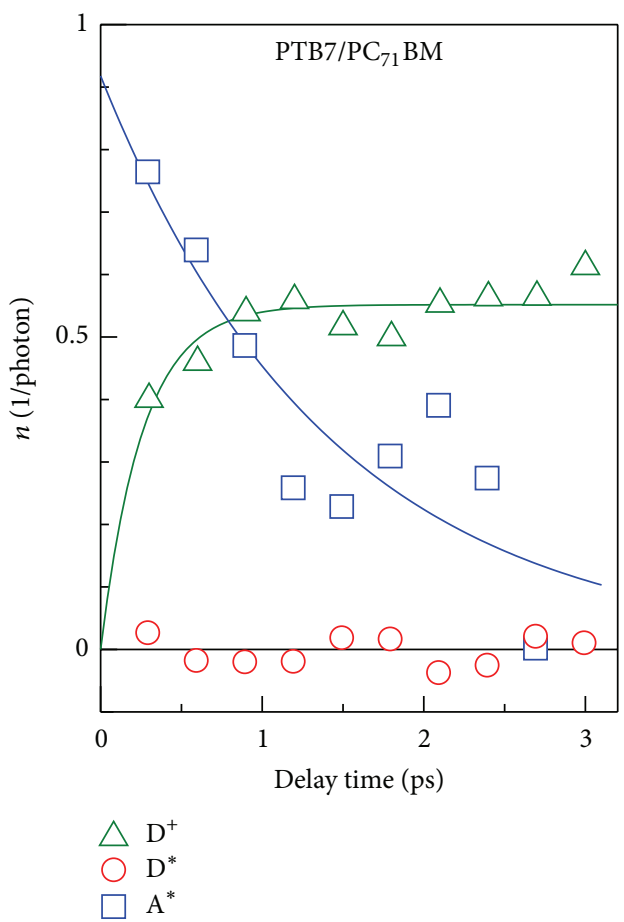

FIGURE 8: Absolute number of carriers $\left(n_{\mathrm{D}^{+}}\right)$, donor excitons $\left(n_{\mathrm{D}^{*}}\right)$, and acceptor excitons $\left(n_{\mathrm{A}^{*}}\right)$ per an absorbed photon against the delay time in PTB7/PC 71 BM blend film. Adjacent averages were plotted in $n_{\mathrm{A}^{*}}$. The solid curves are results of the least-squares fittings with exponential functions.
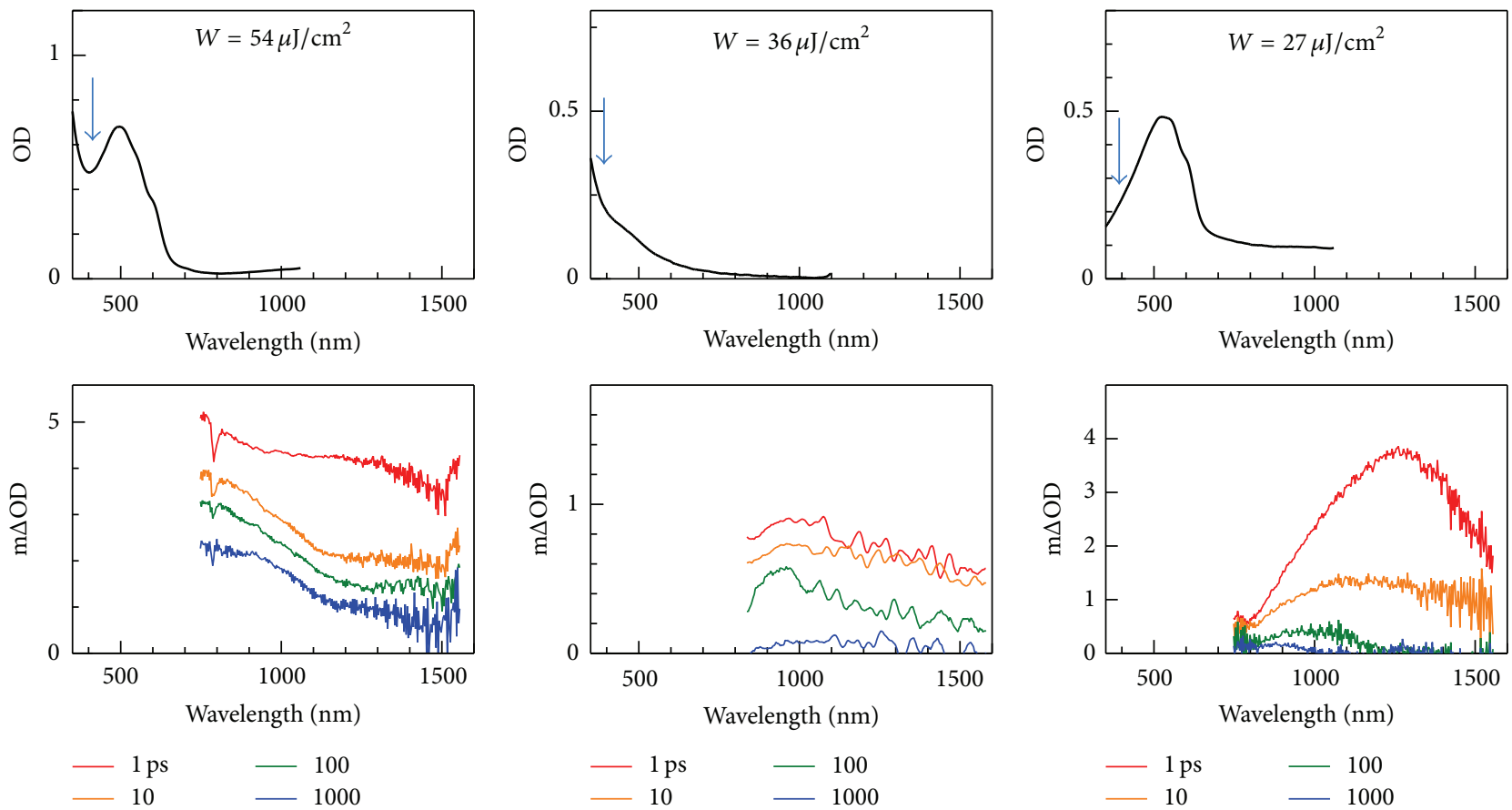

(a)

(b)

(c)

Figure 9: $\triangle$ OD spectra of (a) rr-P3HT/PCBM blend, (b) PCBM neat, and (c) rr-P3HT neat films at $300 \mathrm{~K}$. Top panels show optical density (OD) of the films at $300 \mathrm{~K}$. Downward arrows represent the wavelength of the pump pulse. The data were replotted from [46]. 

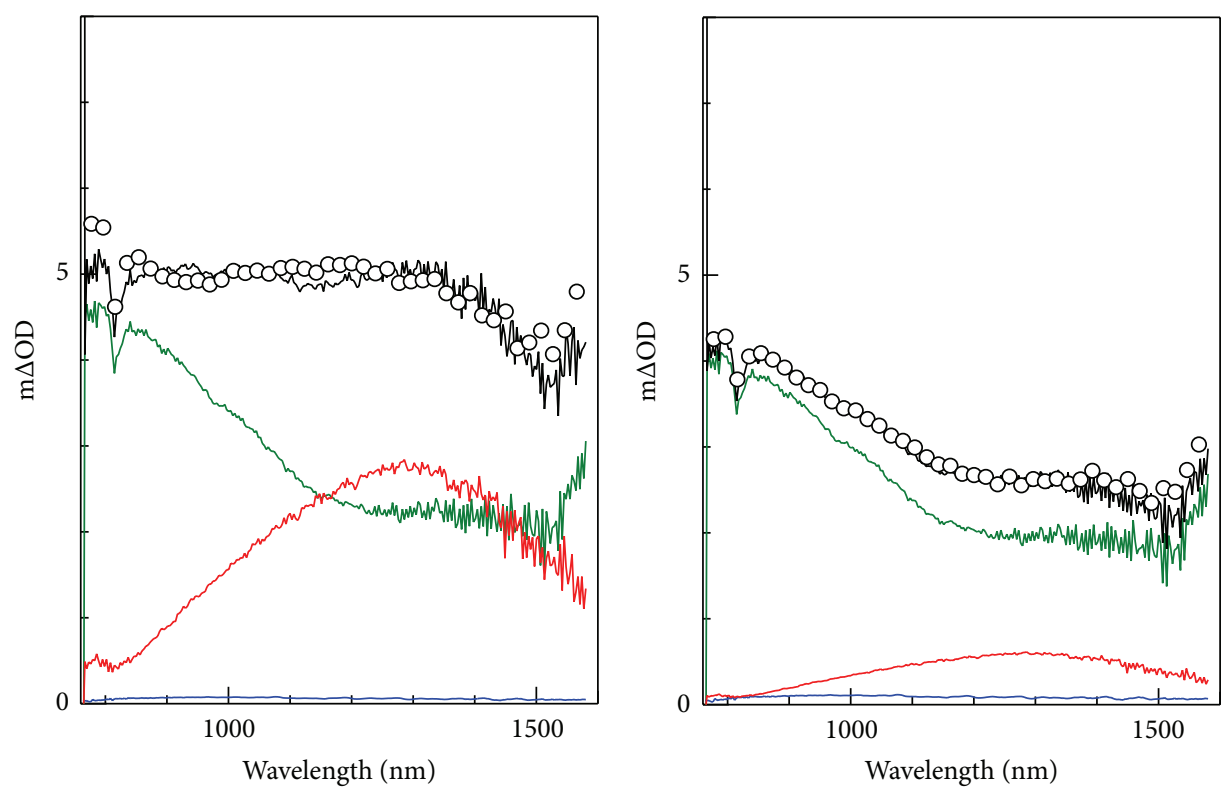

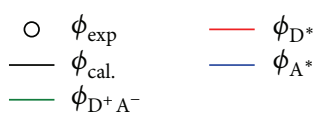

(a)

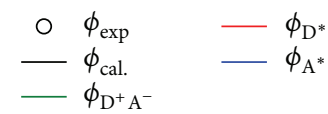

(b)

FIGURE 10: $\triangle$ OD spectra of rr-P3HT/PCBM blend film at (a) $0.3 \mathrm{ps}$ and (b) $4.1 \mathrm{ps}$ at $300 \mathrm{~K}$. Solid curves are results of the decomposition into $\phi_{\mathrm{D}^{+} \mathrm{A}^{-}}, \phi_{\mathrm{A}^{*}}$, and $\phi_{\mathrm{D}^{*}}$.

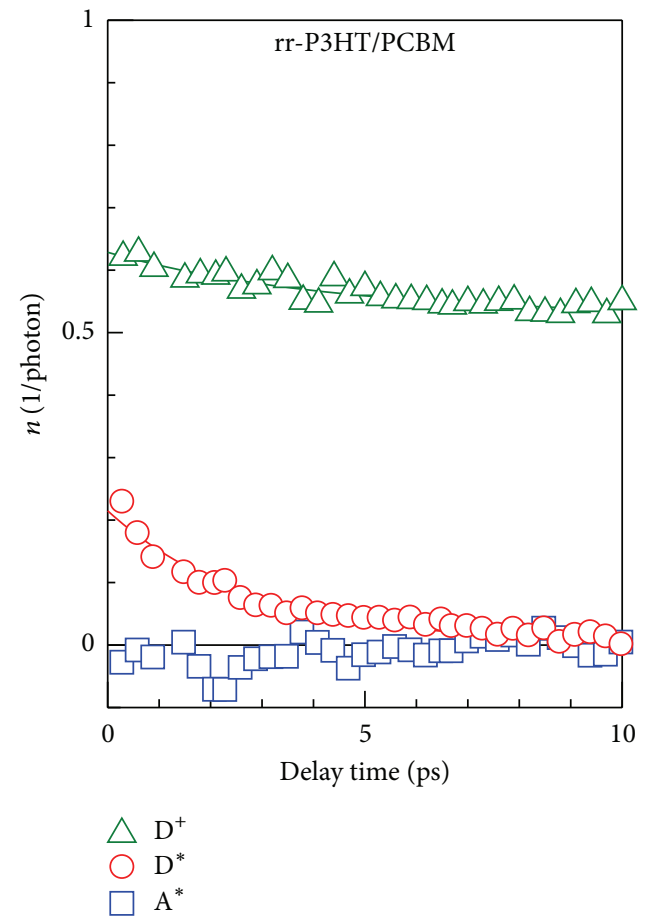

FIGURE 11: $n_{\mathrm{D}^{+}}, n_{\mathrm{D}^{*}}$, and $n_{\mathrm{A}^{*}}$ per an absorbed photon against the delay time in rr-P3HT/PCBM blend film. Adjacent averages were plotted in $n_{\mathrm{A}^{*}}$. The solid curves are results of the least-squares fittings with exponential functions. 

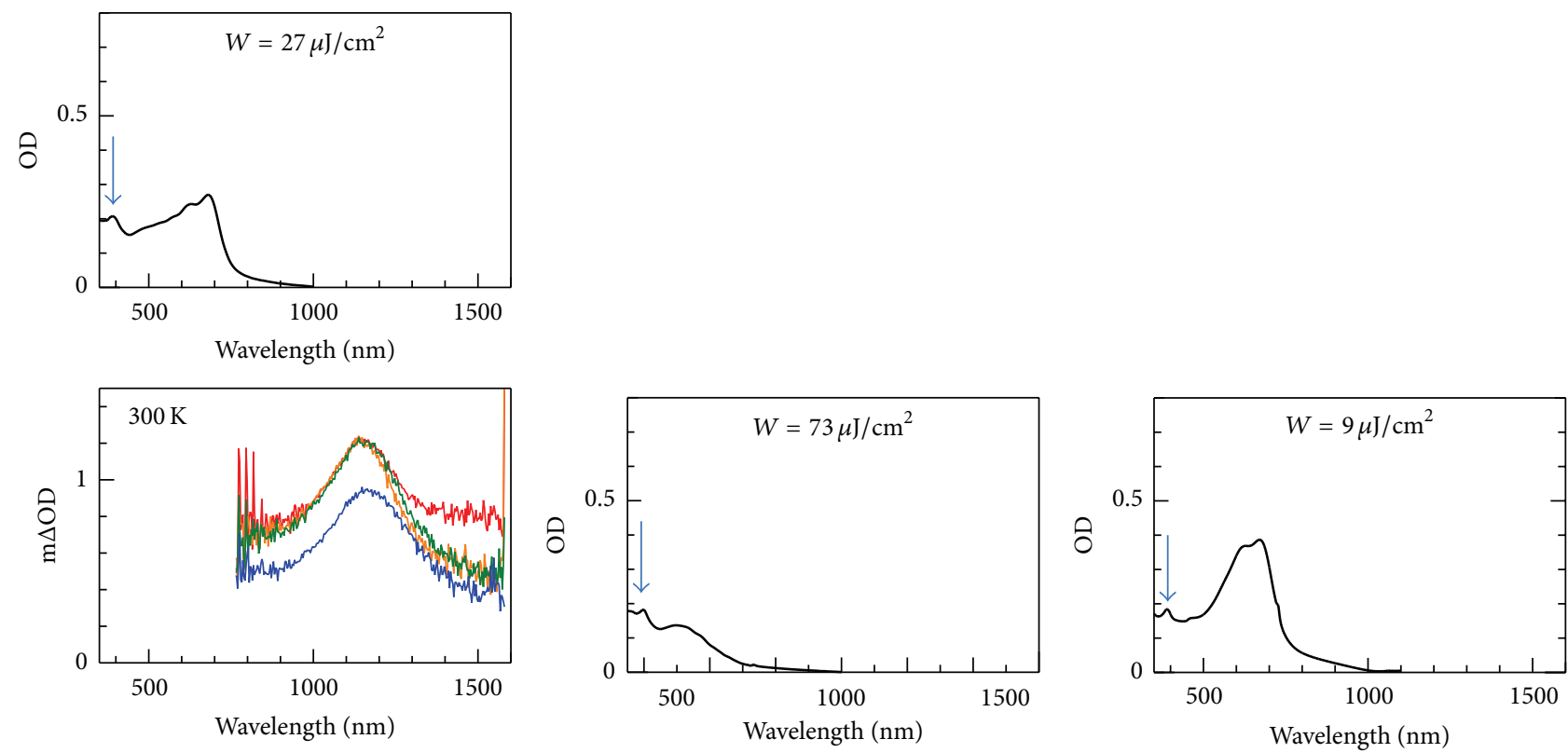

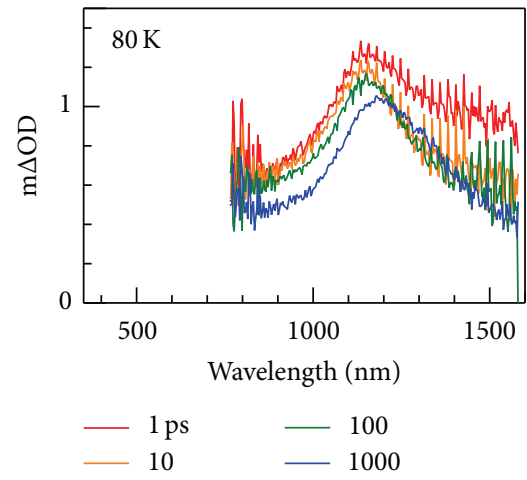

(a)

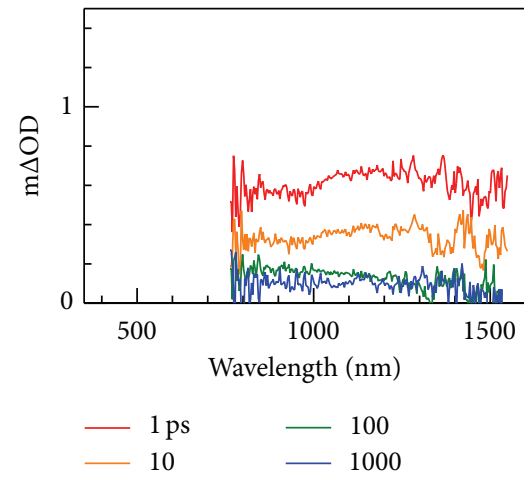

(b)

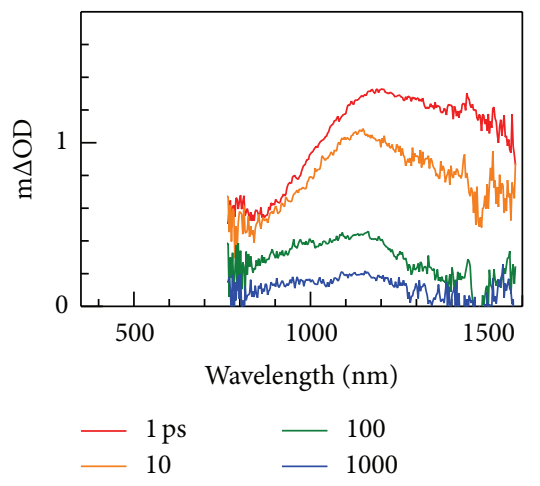

(c)

Figure 12: $\triangle \mathrm{OD}$ spectra of (a) PTB7/C $\mathrm{C}_{70}$ bilayer, (b) $\mathrm{C}_{70}$ neat, and (c) PTB7 neat films. Top panels show optical density (OD) of the films at $300 \mathrm{~K}$. Downward arrows represent the wavelength of the pump pulse. The data were replotted from [59].

a shoulder-like structure, which is analogous to $\triangle \mathrm{OD}_{\mathrm{EC}}$ spectrum [Figure 7(a)] of rr-P3HT neat film. Therefore, the PIA in the late stage can be used as $\phi_{\mathrm{D}^{+} \mathrm{A}^{-}} \phi_{\mathrm{A}^{*}}$ is obtained from $\triangle$ OD spectra [Figure 9(b)] of PCBM neat film, while $\phi_{\mathrm{D}^{*}}$ is obtained from $\triangle \mathrm{OD}$ spectra [Figure 9(c)] of rr-P3HT neat film.

By means of the least-squares fitting, $\phi_{\exp }$ were decomposed into $\phi_{\mathrm{D}^{+} \mathrm{A}^{-}}, \phi_{\mathrm{A}^{*}}$, and $\phi_{\mathrm{D}^{*}}$. The PIA of the blend film at $3 \mathrm{ps}$ was used as $\phi_{\mathrm{D}^{+} \mathrm{A}^{-}}$. The PIA of the PCBM neat film at $1 \mathrm{ps}$ was used as $\phi_{\mathrm{A}^{*}}$. The PIA of rr-P3HT neat film at $1 \mathrm{ps}$ was used as $\phi_{\mathrm{D}^{*}}$. Figure 10 shows examples of the decomposition of the PIA spectra of rr-P3HT/PCBM blend film into $\phi_{\mathrm{D}^{+} \mathrm{A}^{-}}, \phi_{\mathrm{A}^{*}}$, and $\phi_{\mathrm{D}^{*}}$. In order to spectroscopically evaluate $n_{\mathrm{D}^{+}}, n_{\mathrm{D}^{*}}$, and $n_{\mathrm{A}^{*}}$ per an absorbed photon, we need the absolute intensity of the PIA per unit densities of $\mathrm{D}^{+}$, $\mathrm{D}^{*}$, and $\mathrm{A}^{*}$. The absolute intensity of the PIA due to $\mathrm{D}^{+}$ is evaluated by the electrochemical differential spectroscopy [Figure 7(a)]. The absolute intensity of the PIA due to $\mathrm{D}^{*}\left(\mathrm{~A}^{*}\right)$ is evaluated from $\triangle \mathrm{OD}$ spectrum of rr-P3HT (PCBM) neat film.
4.2. Carrier Formation Dynamics. Figure 11 shows $n_{\mathrm{D}^{+}}, n_{\mathrm{D}^{*}}$, and $n_{\mathrm{A}^{*}}$ per an absorbed photon in rr-P3HT/PCBM blend film against $t$. The solid curves are results of least-squares fittings with exponential functions. The present analysis fails to observe the carrier formation process, because $n_{\mathrm{D}^{+}}$ monotonously decreases with decay time of $4.4 \mathrm{ps}$. One possible reason for this unexpected result is that the carrier formation time is too fast to observe. Consistently, Hwang et al. [32] proposed fast formation $(<0.25 \mathrm{ps})$ of the interfacial charge-transfer states. Another possible reason may be the variation of the cross section of the carrier. The present method assumes constant cross section of the carriers. The extended electronic state of the CT state, however, may enhance the cross section as compared with that of the small polaron state (free carrier). If the cross section of the CT state is higher than that of free carrier, $n_{\mathrm{D}^{+}}$value is overestimated in the early stage. Consistently, Takahashi et al. [86] reported intense PIA due to the CT state at $\alpha$-sexithiophene $(6 \mathrm{~T}) / \mathrm{C}_{60}$ interface below $\sim 10 \mathrm{ps}$. This observation implies high oscillator strength of the CT state. 


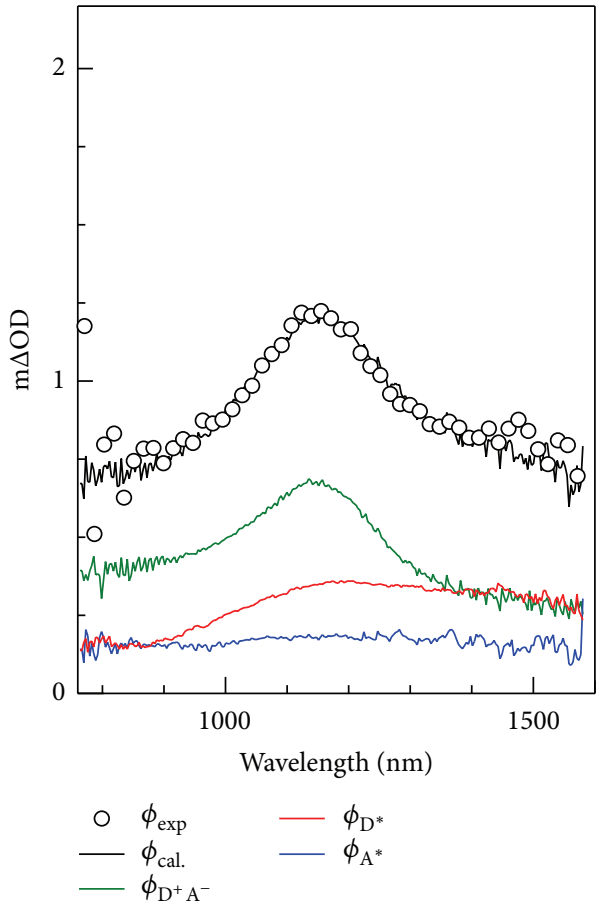

(a)

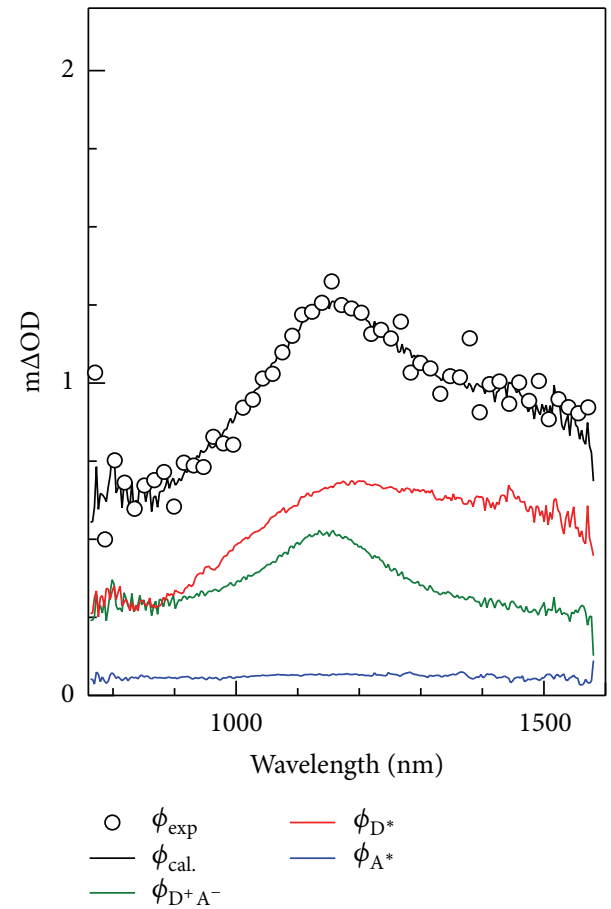

(b)

Figure 13: $\Delta$ OD spectra of PTB7/C 70 bilayer film at 0.9 ps at (a) $300 \mathrm{~K}$ and (b) $80 \mathrm{~K}$. Solid curves are results of the decomposition into $\phi_{\mathrm{D}^{+} \mathrm{A}^{-}}$, $\phi_{\mathrm{A}^{*}}$, and $\phi_{\mathrm{D}^{*}}$.

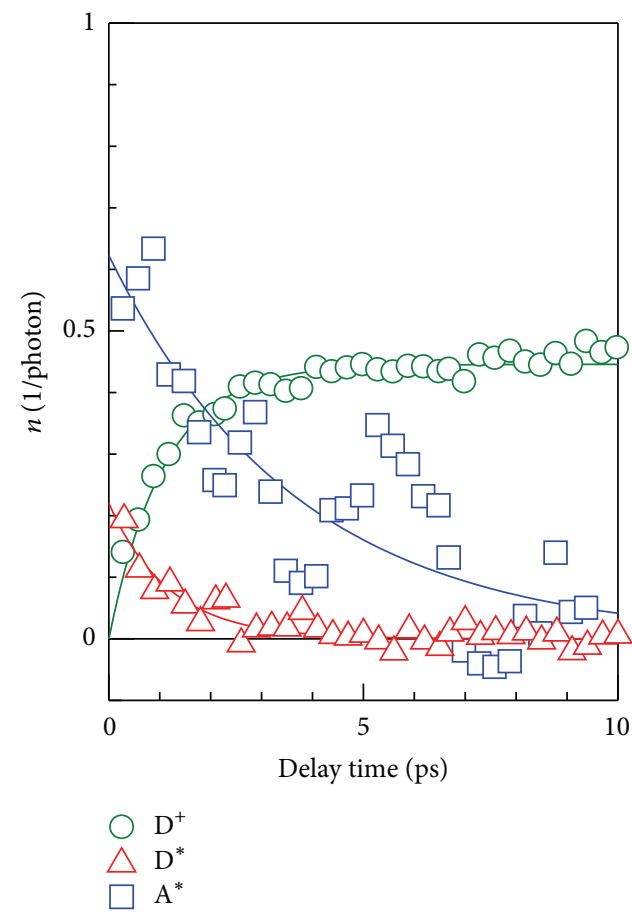

(a)

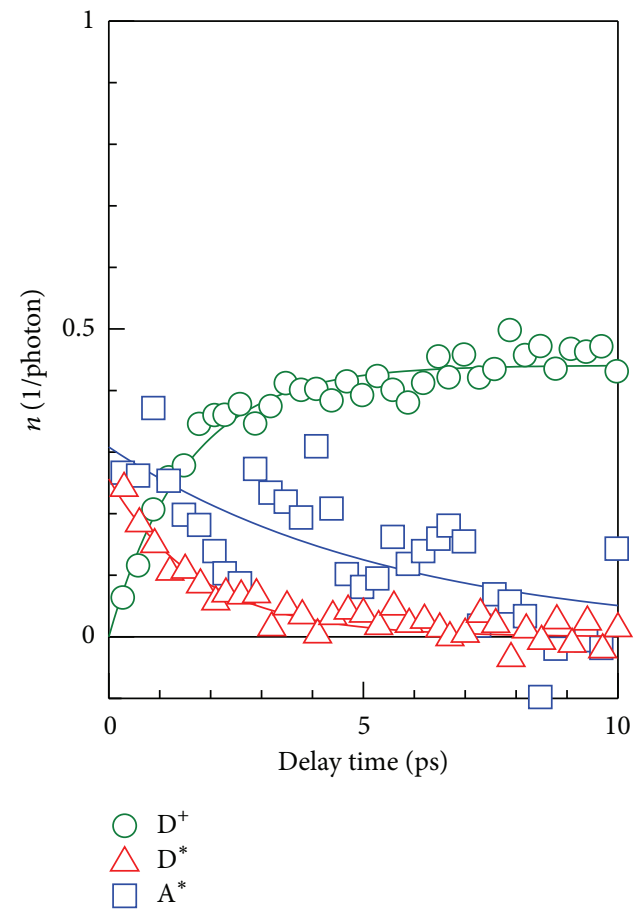

(b)

FIGURE $14: n_{\mathrm{D}^{+}}, n_{\mathrm{D}^{*}}$, and $n_{\mathrm{A}^{*}}$ per an absorbed photon against the delay time in PTB7 $(100 \mathrm{~nm}) / \mathrm{C}_{70}(25 \mathrm{~nm})$ bilayer film at (a) $300 \mathrm{~K}$ and (b) $80 \mathrm{~K}$. Adjacent averages were plotted in $n_{\mathrm{A}^{*}}$. The solid curves are results of the least-squares fittings with exponential functions. 

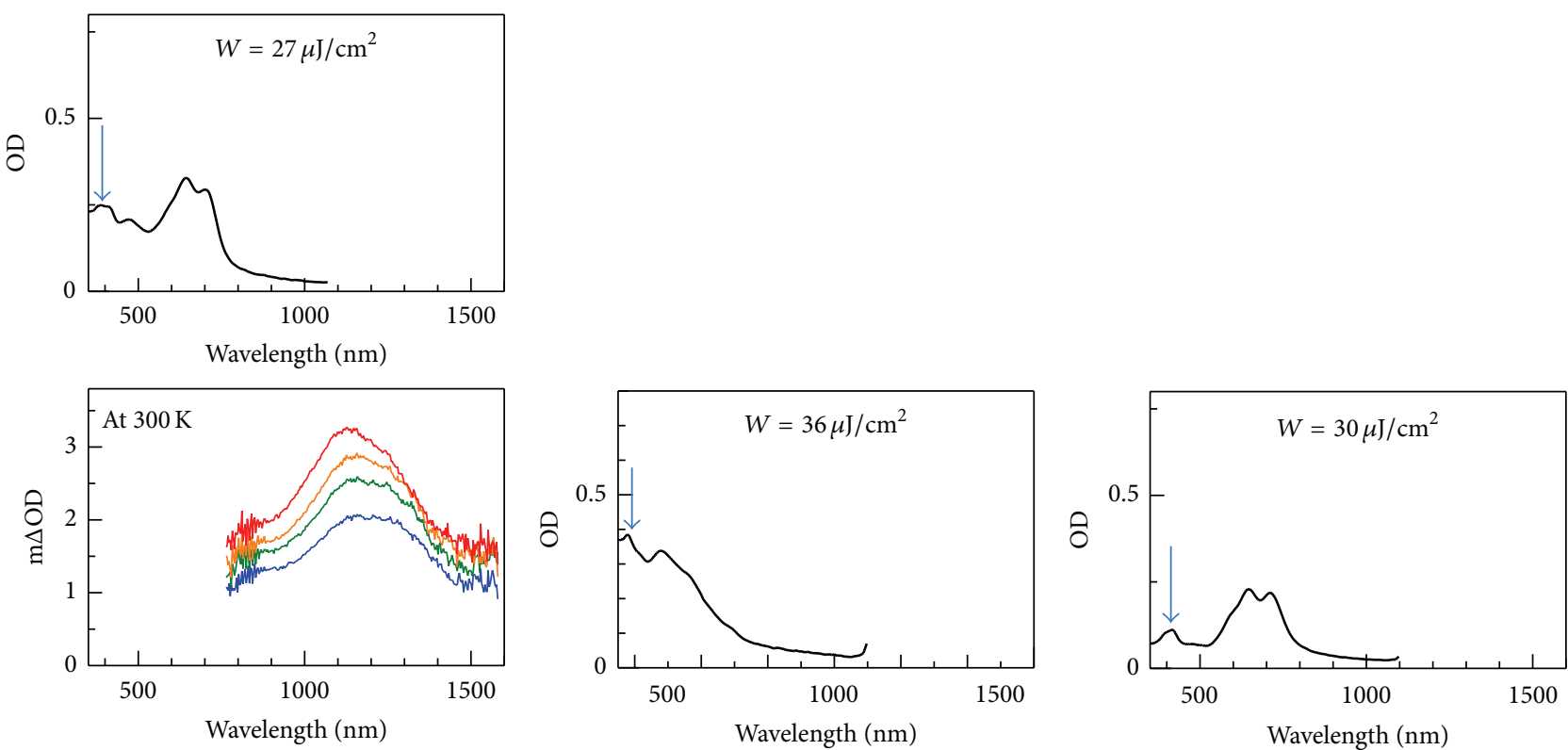

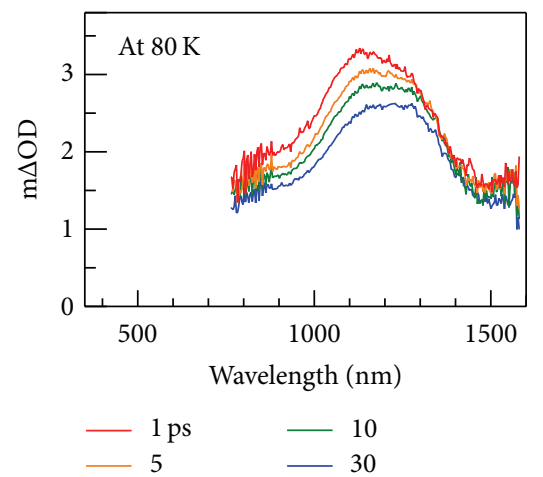

(a)

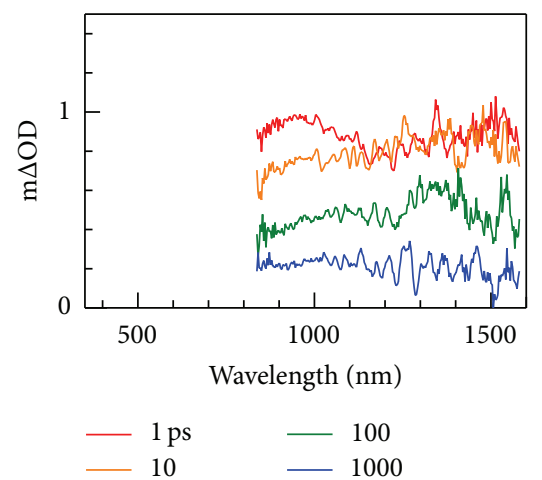

(b)

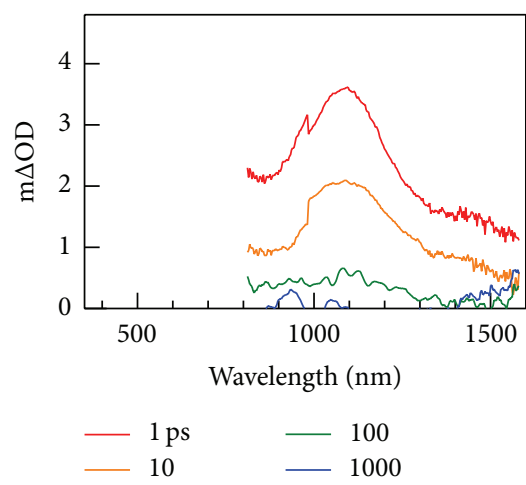

(c)

FIGURE 15: $\triangle \mathrm{OD}$ spectra of (a) SMDPPEH/PC 71 BM blend, (b) $\mathrm{PC}_{71} \mathrm{BM}$ neat, and (c) SMDPPEH neat films. Top panels show optical density (OD) of the films at $300 \mathrm{~K}$. Downward arrows represent the wavelength of the pump pulse. The data were replotted from [60].

On the other hand, $n_{\mathrm{D}^{*}}$ slowly decreases with the decay time $\left(\tau_{\mathrm{D}^{*}}=2.9 \mathrm{ps}\right)$. This indicates that the late decay component of $\mathrm{D}^{*}$ does not contribute to the carrier formation process, similar to the case of $\mathrm{PTB} 7 / \mathrm{PC}_{71} \mathrm{BM}$ blend film.

\section{PTB7/C ${ }_{70}$ Bilayer Film: A HJ System}

5.1. PIA Spectra and Analyses. Figure $12(\mathrm{a})$ shows $\triangle \mathrm{OD}$ spectra of PTB7 $(100 \mathrm{~nm}) / \mathrm{C}_{70}(25 \mathrm{~nm})$ bilayer film. At $300 \mathrm{~K}$, the PIA spectra in the late stage $(>10 \mathrm{ps})$ show broad PIA around $1150 \mathrm{~nm}$. The PIA is originated from the photoinduced carriers $\left(\mathrm{D}^{+}\right)$of PTB7 [57-60]. In the early stage (=1 ps), additional absorption component is observed around $1500 \mathrm{~nm}$. The additional components are reasonably ascribed to the PIA due to $\mathrm{D}^{*}$ and $\mathrm{A}^{*} \cdot \phi_{\mathrm{A}^{*}}$ is obtained from $\Delta \mathrm{OD}$ spectra [Figure 12(b)] of $\mathrm{C}_{70}$ neat film, while $\phi_{\mathrm{D}^{*}}$ is obtained from $\triangle \mathrm{OD}$ spectra [Figure 12(c)] of PTB7 neat film.

By means of the least-squares fitting, $\phi_{\exp }$ were decomposed into $\phi_{\mathrm{D}^{+} \mathrm{A}^{-}}, \phi_{\mathrm{A}^{*}}$, and $\phi_{\mathrm{D}^{*}}$. The PIA of the blend film at 10 ps was used as $\phi_{\mathrm{D}^{+} \mathrm{A}^{-}}$. The PIA of $\mathrm{C}_{70}$ neat film at $1 \mathrm{ps}$ was used as $\phi_{\mathrm{A}^{*}}$. The PIA of PTB7 neat film at 1 ps was used as $\phi_{\mathrm{D}^{*}}$. Figure 13 shows examples of the decomposition of the PIA spectra of PTB7/C 70 bilayer film into $\phi_{\mathrm{D}^{+} \mathrm{A}^{-}}, \phi_{\mathrm{A}^{*}}$, and $\phi_{\mathrm{D}^{*}}$. The absolute intensity of the PIA due to $\mathrm{D}^{+}$is evaluated by the electrochemical differential spectroscopy [Figure 7(a)]. The absolute intensity of the PIA due to $\mathrm{D}^{*}\left(\mathrm{~A}^{*}\right)$ is evaluated from $\triangle \mathrm{OD}$ spectrum of PTB7 $\left(\mathrm{C}_{70}\right)$ neat film. Strictly speaking, the cross sections for the respective species may depend on temperature. In this sense, one should be careful when he discusses temperature effect on the absolute number of $n_{\mathrm{D}^{+}}$, $n_{\mathrm{D}^{*}}$, and $n_{\mathrm{A}^{*}}$. On the other hand, the temporal behaviors of $n_{\mathrm{D}^{+}}, n_{\mathrm{D}^{*}}$, and $n_{\mathrm{A}^{*}}$ are independent of the cross section.

5.2. Carrier Formation Dynamics. Figure 14 shows $n_{\mathrm{D}^{+}}, n_{\mathrm{D}^{*}}$, and $n_{\mathrm{A}^{*}}$ per an absorbed photon in PTB7 $(100 \mathrm{~nm}) / \mathrm{C}_{70}$ $(25 \mathrm{~nm})$ bilayer film at (a) $300 \mathrm{~K}$ and (b) $80 \mathrm{~K}$ against $t$. The solid curves are results of least-squares fittings with exponential functions. At $300 \mathrm{~K}$ [Figure 14(a)], the carrier formation time $\left(\tau_{\mathrm{D}^{+}}=1.1 \mathrm{ps}\right)$ is rather slow as compared with that $(=0.3 \mathrm{ps})$ in the BHJ system. Slower $\tau_{\mathrm{D}^{+}}$is ascribed to 


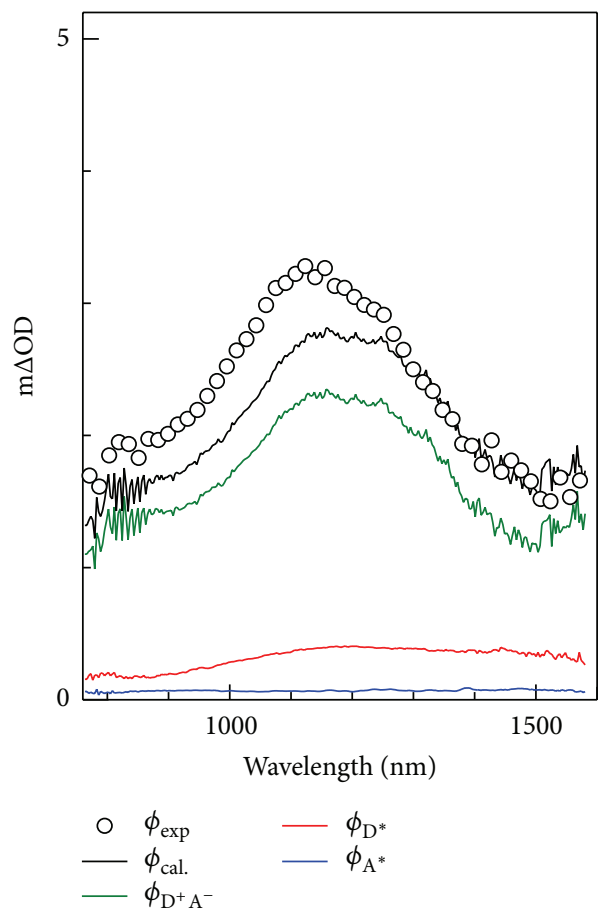

(a)

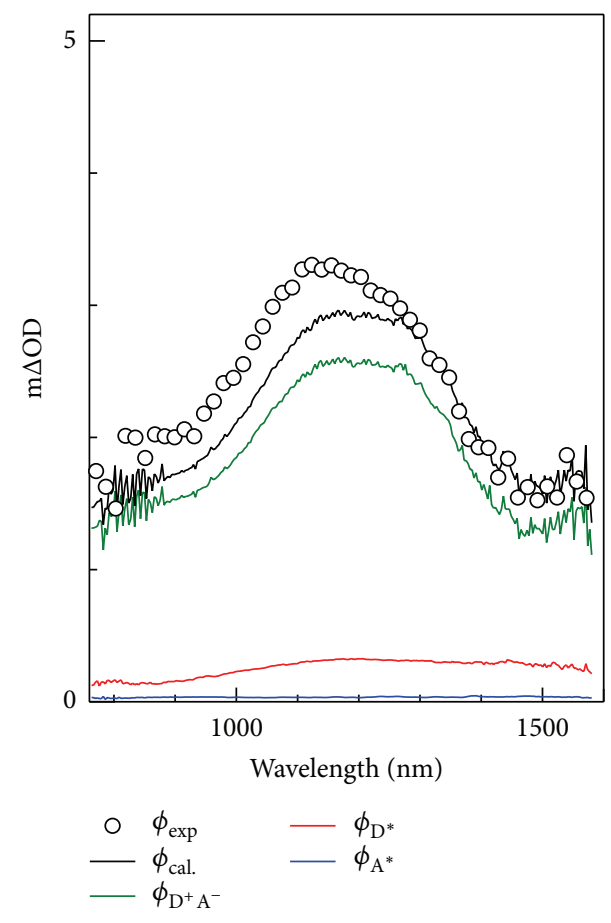

(b)

FIGURE 16: $\triangle \mathrm{OD}$ spectra of SMDPPEH/PC ${ }_{71} \mathrm{BM}$ blend film at $0.9 \mathrm{ps}$ at (a) $300 \mathrm{~K}$ and (b) $80 \mathrm{~K}$. Solid curves are results of the decomposition into $\phi_{\mathrm{D}^{+} \mathrm{A}^{-}}, \phi_{\mathrm{A}^{*}}$, and $\phi_{\mathrm{D}^{*}}$.

thicker domain in the heterojunction system and resultant long journey of the excitons to D/A interface. Decay time $\left(\tau_{\mathrm{D}^{*}}=1.2 \mathrm{ps}\right)$ of $\mathrm{D}^{*}$ is comparable to $\tau_{\mathrm{D}^{+}}(=1.1 \mathrm{ps})$, indicating an efficient conversion process from $\mathrm{D}^{*}$ to the carrier. Decay time $\left(\tau_{\mathrm{A}^{*}}=3.5 \mathrm{ps}\right)$ of $\mathrm{A}^{*}$, however, is much longer than $\tau_{\mathrm{D}^{+}}$ $(=1.1 \mathrm{ps})$. This indicates that the late decay component of $\mathrm{A}^{*}$ does not contribute to the carrier formation process, similar to the case of PTB7/PC $\mathrm{P}_{71} \mathrm{BM}$ blend film.

Overall carrier formation dynamics at $80 \mathrm{~K}$ [Figure 14(b)] is similar to that at $300 \mathrm{~K}$ [Figure 14(a)]. In particular, the carrier formation efficiency ( $=0.5$ carriers/absorbed photon) at $80 \mathrm{~K}$ is almost the same as that at $300 \mathrm{~K}$. Thus, the transient absorption spectroscopy revealed that the exciton-carrier conversion process is insensitive to temperature. We emphasize that PCE of OCS steeply decreases with decrease in temperature, because carrier transport process is significantly sensitive to temperature. This observation, together with the fast carrier formation time in OSCs [32, 41], is consistent with the hot exciton picture. The low temperature effect is the elongation of carrier formation $\left(\tau_{\mathrm{D}^{+}}=1.5 \mathrm{ps}\right)$ and exciton decay $\left(\tau_{\mathrm{D}^{*}}=1.8 \mathrm{ps}\right.$ and $\left.\tau_{\mathrm{A}^{*}}=5.1 \mathrm{ps}\right)$ times.

\section{SMDPPEH/PC ${ }_{71}$ BM Blend Film: Small Molecule System}

6.1. PIA Spectra and Analyses. Figure 15(a) shows $\triangle \mathrm{OD}$ spectra of SMDPPEH/PC ${ }_{71} \mathrm{BM}$ blend film. At $300 \mathrm{~K}$, the PIA spectra show a broad absorption band in the infrared region. The peak position shifts show a red-shift from $1100 \mathrm{~nm}$ at $1 \mathrm{ps}$ to $1200 \mathrm{~nm}$ at $10 \mathrm{ps}$. The red-shift disappears above $10 \mathrm{ps}$ and the spectral profile becomes independent of $t$. Therefore, the PIA in the late stage can be used as $\phi_{\mathrm{D}^{+} \mathrm{A}^{-}} . \phi_{\mathrm{A}^{*}}$ is obtained from $\triangle \mathrm{OD}$ spectra [Figure $15(\mathrm{~b})$ ] of $\mathrm{PC}_{71} \mathrm{BM}$ neat film, while $\phi_{\mathrm{D}^{*}}$ is obtained from $\triangle \mathrm{OD}$ spectra [Figure $15(\mathrm{c})$ ] of SMDPPEH neat film.

By means of the least-squares fitting, $\phi_{\exp }$ were decomposed into $\phi_{\mathrm{D}^{+} \mathrm{A}^{-}}, \phi_{\mathrm{A}^{*}}$, and $\phi_{\mathrm{D}^{*}}$. The PIA of the blend film at $10 \mathrm{ps}$ was used as $\phi_{\mathrm{D}^{+} \mathrm{A}^{-}}$. The PIA of $\mathrm{PC}_{71} \mathrm{BM}$ neat film at $1 \mathrm{ps}$ was used as $\phi_{\mathrm{A}^{*}}$. The PIA of SMDPPEH neat film at $1 \mathrm{ps}$ was used as $\phi_{\mathrm{D}^{*}}$. Figure 16 shows examples of the decomposition of the PIA spectra of SMDPPEH/PC ${ }_{71} \mathrm{BM}$ blend film into $\phi_{\mathrm{D}^{+} \mathrm{A}^{-}}, \phi_{\mathrm{A}^{*}}$, and $\phi_{\mathrm{D}^{*}}$. The absolute intensity of the PIA due to $\mathrm{D}^{*}\left(\mathrm{~A}^{*}\right)$ is evaluated from $\triangle \mathrm{OD}$ spectrum of SMDPPEH $\left(\mathrm{PC}_{71} \mathrm{BM}\right)$ neat film. It was difficult to obtain a quantitative electrochemical differential spectra, because the SMDPPEH molecule is solvable to the organic electrolyte.

6.2. Carrier Formation Dynamics. Figure 17 shows $n_{\mathrm{D}^{+}}, n_{\mathrm{D}^{*}}$, and $n_{\mathrm{A}^{*}}$ per an absorbed photon in SMDPPEH/PC 71 BM blend film at (a) $300 \mathrm{~K}$ and (b) $80 \mathrm{~K}$ against $t$. The solid curves are results of least-squares fittings with exponential functions. At $300 \mathrm{~K}$ [Figure 16(a)], carrier formation time ( $\tau_{\mathrm{D}^{+}}=0.4 \mathrm{ps}$ ) is very fast. Fast $\tau_{\mathrm{D}^{+}}$is ascribed to the nanosize domain structure of the $\mathrm{BHJ}$. Decay time $\left(\tau_{\mathrm{A}^{*}}=0.4 \mathrm{ps}\right)$ of $\mathrm{A}^{*}$ is comparable to $\tau_{\mathrm{D}^{+}}(=0.4 \mathrm{ps})$, indicating an efficient conversion process from $\mathrm{A}^{*}$ to the carrier. Decay time $\left(\tau_{\mathrm{D}^{*}}=\right.$ $2.6 \mathrm{ps})$ of $\mathrm{D}^{*}$, however, is much longer than $\tau_{\mathrm{D}^{+}}(=0.4 \mathrm{ps})$. This indicates that the late decay component of $\mathrm{A}^{*}$ does not 

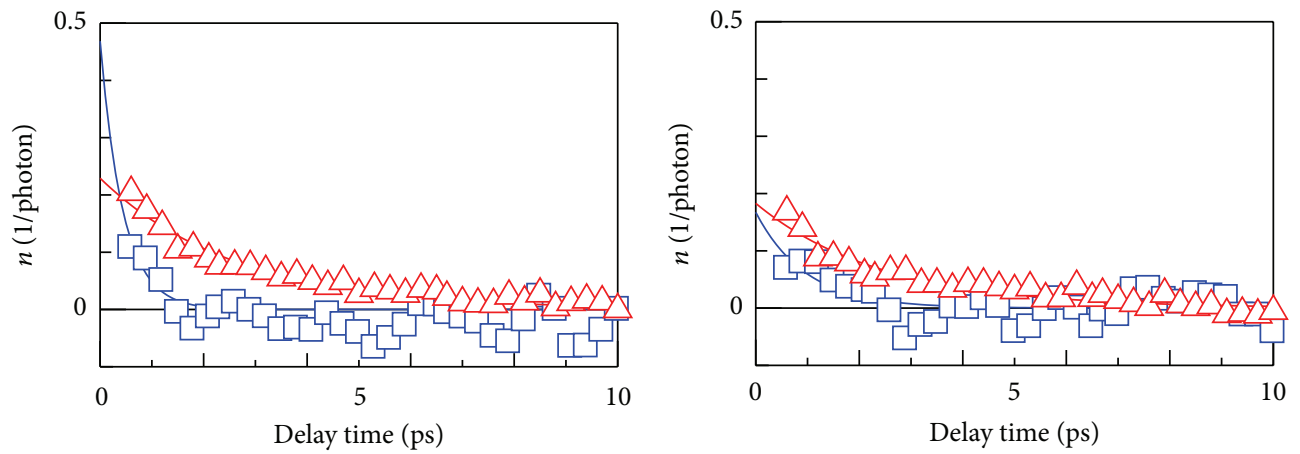

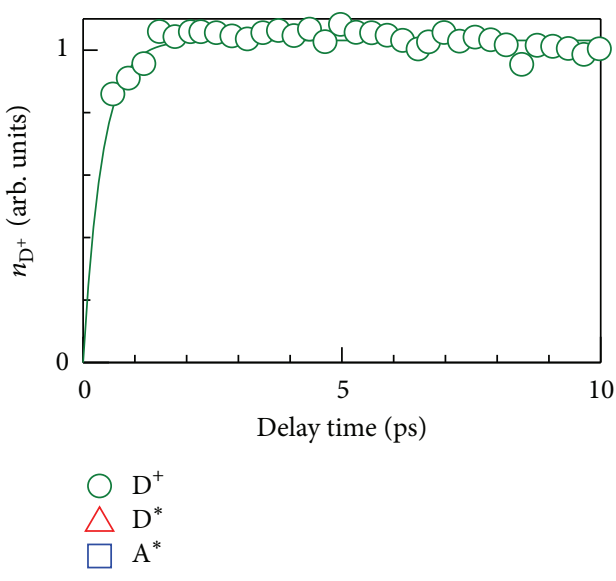

(a)

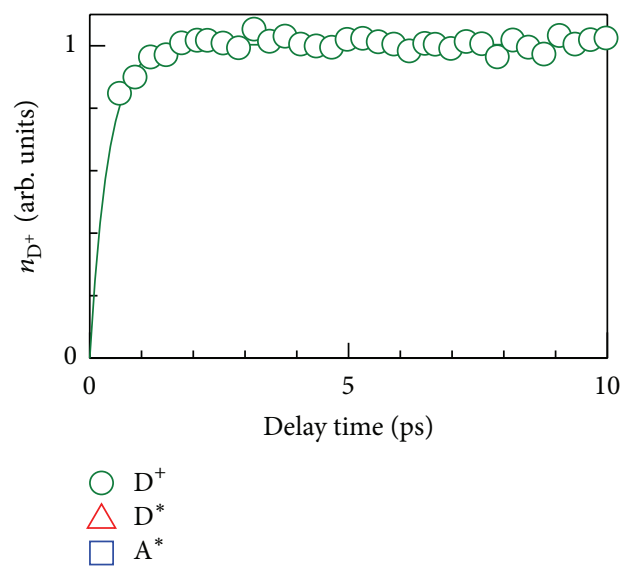

(b)

FIGURE $17: n_{\mathrm{D}^{+}}, n_{\mathrm{D}^{*}}$, and $n_{\mathrm{A}^{*}}$ per an absorbed photon against the delay time in SMDPPEH/PC $\mathrm{P}_{71} \mathrm{BM}$ blend film at (a) $300 \mathrm{~K}$ and (b) $80 \mathrm{~K}$. Adjacent averages were plotted in $n_{\mathrm{A}^{*}}$. The solid curves are results of the least-squares fittings with exponential functions.

contribute to the carrier formation process, similar to the case of PTB7/PC ${ }_{71}$ BM blend film.

Overall carrier formation dynamics at $80 \mathrm{~K}$ [Figure 17(b)] is similar to that at $300 \mathrm{~K}$ [Figure $17(\mathrm{a})$ ], similar to the case of PTB7/ $\mathrm{C}_{70}$ bilayer film. The low temperature effect is the elongation of decay time $\left(\tau_{\mathrm{A}^{*}}=1.0\right)$ of $\mathrm{A}^{*}$.

\section{Summary}

We applied a new method, which determines the absolute numbers of the excitons and carriers only from the PIA and EIA spectra, to (i) $\mathrm{PTB} 7 / \mathrm{PC}_{71} \mathrm{BM}$ blend, (ii) rr-P3HT/PCBM blend, (iii) PTB7/ $\mathrm{C}_{70}$ bilayer, and (iv) SMDPPEH/PC $\mathrm{P}_{71} \mathrm{BM}$ blend films. The analyses revealed important common features on the carrier formation dynamics in the OSCs. First, the late decay component of exciton does not contribute to the carrier formation process, as observed in the (i) $\mathrm{PTB} 7 / \mathrm{PC}_{71} \mathrm{BM}$ blend, (ii) rr-P3HT/PCBM blend, (iii) PTB7/C 70 bilayer, and (iv) SMDPPEH/PC $\mathrm{C}_{71}$ BM blend films. This is probably because the late component has not enough excess energy to separate into electron and hole at D/A interface. Secondly, entire carrier formation dynamics is insensitive to temperature, as observed in (iii) $\mathrm{PTB} 7 / \mathrm{C}_{70}$ bilayer and (iv) SMDPPEH/PC ${ }_{71}$ BM blend films. This observation, together with the fast carrier formation time in OSCs $[32,41]$, is consistent with the hot exciton picture.

\section{Competing Interests}

The authors declare that they have no competing interests.

\section{Acknowledgments}

This work was supported by Futaba Electronics Memorial Foundation and a Grant-in-Aid for Young Scientists (B) (22750176) from Scientific Research from the Ministry of Education, Culture, Sports, Science and Technology, Japan.

\section{References}

[1] M. Hiramoto, H. Fujiwara, and M. Yokoyama, “Three-layered organic solar cell with a photoactive interlayer of codeposited pigments," Applied Physics Letters, vol. 58, no. 10, pp. 1062-1064, 1991.

[2] N. S. Sariciftci, L. Smilowitz, A. J. Heeger, and F. Wudl, "Photoinduced electron transfer from a conducting polymer to buckminsterfullerene," Science, vol. 258, no. 5087, pp. 1474-1476, 1992.

[3] K. A. Mazzio and C. K. Luscombe, "The future of organic photovoltaics," Chemical Society Reviews, vol. 44, no. 1, pp. 7890, 2015.

[4] M. C. Scharber, "On the efficiency limit of conjugated polymer: fullerene-based bulk heterojunction solar cells," Advanced Materials, vol. 28, no. 10, pp. 1994-2001, 2016. 
[5] I. Etxebarria, J. Ajuria, and R. Pacios, "Solution-processable polymeric solar cells: a review on materials, strategies and cell architectures to overcome 10\%," Organic Electronics, vol. 19, pp. 34-60, 2015.

[6] H.-C. Liao, C.-C. Ho, C.-Y. Chang, M.-H. Jao, S. B. Darling, and W.-F. Su, "Additives for morphology control in high-efficiency organic solar cells," Materials Today, vol. 16, no. 9, pp. 326-336, 2013.

[7] S. Y. Leblebici, T. L. Chen, P. Olalde-Velasco, W. Yang, and B. $\mathrm{Ma}$, "Reducing exciton binding energy by increasing thin film permittivity: an effective approach to enhance exciton separation efficiency in organic solar cells," ACS Applied Materials and Interfaces, vol. 5, no. 20, pp. 10105-10110, 2013.

[8] N. Camaioni and R. Po, "Pushing the envelope of the intrinsic limitation of organic solar cells," Journal of Physical Chemistry Letters, vol. 4, no. 11, pp. 1821-1828, 2013.

[9] T. K. Mullenbach, K. A. McGarry, W. A. Luhman, C. J. Douglas, and R. J. Holmes, "Connecting molecular structure and exciton diffusion length in rubrene derivatives," Advanced Materials, vol. 25, no. 27, pp. 3689-3693, 2013.

[10] F. Gao and O. Inganäs, "Charge generation in polymer-fullerene bulk-heterojunction solar cells," Physical Chemistry Chemical Physics, vol. 16, no. 38, pp. 20291-20304, 2014.

[11] P. W. M. Blom, V. D. Mihailetchi, L. J. A. Koster, and D. E. Markov, "Device physics of polymer: fullerene bulk heterojunction solar cells," Advanced Materials, vol. 19, no. 12, pp. 15511566, 2007.

[12] T. M. Clarke and J. R. Durrant, "Charge photogeneration in organic solar cells," Chemical Reviews, vol. 110, no. 11, pp. 6736$6767,2010$.

[13] J.-L. Brédas, J. E. Norton, J. Cornil, and V. Coropceanu, "Molecular understanding of organic solar cells: the challenges," Accounts of Chemical Research, vol. 42, no. 11, pp. 1691-1699, 2009.

[14] C. Deibe, T. Strobe, and V. Dyakonov, "Role of the charge transfer state in organic donor-acceptor solar cells," Advanced Materials, vol. 22, no. 37, pp. 4097-4111, 2010.

[15] C. Deibel and V. Dyakonov, "Polymer-fullerene bulk heterojunction solar cells," Reports on Progress in Physics, vol. 73, no. 9, Article ID 096401, 2010.

[16] C. Piliego and M. A. Loi, "Charge transfer state in highly efficient polymer-fullerene bulk heterojunction solar cells," Journal of Materials Chemistry, vol. 22, no. 10, pp. 4141-4150, 2012.

[17] C. Groves, "Developing understanding of organic photovoltaic devices: kinetic Monte Carlo models of geminate and nongeminate recombination, charge transport and charge extraction," Energy and Environmental Science, vol. 6, no. 11, pp. 32023217, 2013.

[18] R. A. J. Janssen and J. Nelson, "Factors limiting device efficiency in organic photovoltaics," Advanced Materials, vol. 25, no. 13, pp. 1847-1858, 2013.

[19] G. Lakhwani, A. Rao, and R. H. Friend, "Bimolecular recombination in organic photovoltaics," Annual Review of Physical Chemistry, vol. 65, pp. 557-581, 2014.

[20] L. Goris, A. Poruba, L. Hod'ákova et al., "Observation of the subgap optical absorption in polymer-fullerene blend solar cells," Applied Physics Letters, vol. 88, no. 5, Article ID 052113, 2006.

[21] S. Ko, E. T. Hoke, L. Pandey et al., "Controlled conjugated backbone twisting for an increased open-circuit voltage while having a high short-circuit current in poly(hexylthiophene) derivatives," Journal of the American Chemical Society, vol. 134, no. 11, pp. 5222-5232, 2012.

[22] K. Vandewal, K. Tvingstedt, A. Gadisa, O. Inganäs, and J. V. Manca, "On the origin of the open-circuit voltage of polymerfullerene solar cells," Nature Materials, vol. 8, no. 11, pp. 904909, 2009.

[23] K. Vandewal, A. Gadisa, W. D. Oosterbaan et al., "The relation between open-circuit voltage and the onset of photocurrent generation by charge-transfer absorption in polymer: fullerene bulk heterojunction solar cells," Advanced Functional Materials, vol. 18, no. 14, pp. 2064-2070, 2008.

[24] E. T. Hoke, K. Vandewal, J. A. Bartelt et al., "Recombination in polymer: fullerene solar cells with open-circuit voltages approaching and exceeding 1.0 V," Advanced Energy Materials, vol. 3, no. 2, pp. 220-230, 2013.

[25] Y. Zhou, K. Tvingstedt, F. Zhang et al., "Observation of a charge transfer state in low-bandgap polymer/fullerene blend systems by photoluminescence and electroluminescence studies," Advanced Functional Materials, vol. 19, no. 20, pp. 3293$3299,2009$.

[26] K. Tvingstedt, K. Vandewal, A. Gadisa, F. Zhang, J. Manca, and O. Inganäs, "Electroluminescence from charge transfer states in polymer solar cells," Journal of the American Chemical Society, vol. 131, no. 33, pp. 11819-11824, 2009.

[27] D. Veldman, Ö. Ipek, S. C. J. Meskers et al., "Compositional and electric field dependence of the dissociation of charge transfer excitons in alternating polyfluorene copolymer/fullerene blends," Journal of the American Chemical Society, vol. 130, no. 24, pp. 7721-7735, 2008.

[28] J. Niklas, S. Beaupré, M. Leclerc et al., "Photoinduced dynamics of charge separation: from photosynthesis to polymer-fullerene bulk heterojunctions," Journal of Physical Chemistry B, vol. 119, no. 24, pp. 7407-7416, 2015.

[29] L. Franco, A. Toffoletti, M. Ruzzi et al., "Time-resolved EPR of photoinduced excited states in a semiconducting polymer/PCBM blend," The Journal of Physical Chemistry C, vol. 117, no. 4, pp. 1554-1560, 2013.

[30] Y. Kobori, R. Noji, and S. Tsuganezawa, "Initial molecular photocurrent: nanostructure and motion of weakly bound charge-separated state in organic photovoltaic interface," The Journal of Physical Chemistry C, vol. 117, no. 4, pp. 1589-1599, 2013.

[31] J. Behrends, A. Sperlich, A. Schnegg et al., "Direct detection of photoinduced charge transfer complexes in polymer fullerene blends," Physical Review B, vol. 85, no. 12, Article ID 125206, 2012.

[32] I.-W. Hwang, D. Moses, and A. J. Heeger, "Photoinduced carrier generation in $\mathrm{P} 3 \mathrm{HT} / \mathrm{PCBM}$ bulk heterojunction materials," The Journal of Physical Chemistry C, vol. 112, no. 11, pp. 4350-4354, 2008.

[33] J. Guo, H. Ohkita, H. Benten, and S. Ito, "Near-IR femtosecond transient absorption spectroscopy of ultrafast polaron and triplet exciton formation in polythiophene films with different regioregularities," Journal of the American Chemical Society, vol. 131, no. 46, pp. 16869-16880, 2009.

[34] J. Guo, H. Ohkita, H. Benten, and S. Ito, "Charge generation and recombination dynamics in poly(3-hexylthiophene)/fullerene blend films with different regioregularities and morphologies," Journal of the American Chemical Society, vol. 132, no. 17, pp. 6154-6164, 2010. 
[35] R. A. Marsh, J. M. Hodgkiss, S. Albert-Seifried, and R. H. Friend, "Effect of annealing on P3HT: PCBM charge transfer and nanoscale morphology probed by ultrafast spectroscopy," Nano Letters, vol. 10, no. 3, pp. 923-930, 2010.

[36] M. Tong, N. E. Coates, D. Moses, A. J. Heeger, S. Beaupré, and M. Leclerc, "Charge carrier photogeneration and decay dynamics in the poly(2,7-carbazole) copolymer PCDTBT and in bulk heterojunction composites with PC70 BM," Physical Review B, vol. 81, no. 12, Article ID 125210, 2010.

[37] S. De, T. Kesti, M. Maiti et al., "Exciton dynamics in alternating polyfluorene/fullerene blends," Chemical Physics, vol. 350, no. 1-3, pp. 14-22, 2008.

[38] S. K. Pal, T. Kesti, M. Maiti et al., "Geminate charge recombination in polymer/fullerene bulk heterojunction films and implications for solar cell function," Journal of the American Chemical Society, vol. 132, no. 35, pp. 12440-12451, 2010.

[39] I. A. Howard, R. Mauer, M. Meister, and F. Laquai, "Effect of morphology on ultrafast free carrier generation in polythiophene: fullerene organic solar cells," Journal of the American Chemical Society, vol. 132, no. 42, pp. 14866-14876, 2010.

[40] I. A. Howard and F. Laquai, "Optical probes of charge generation and recombination in bulk heterojunction organic solar cells," Macromolecular Chemistry and Physics, vol. 211, no. 19, pp. 2063-2070, 2010.

[41] G. Grancini, M. Maiuri, D. Fazzi et al., "Hot exciton dissociation in polymer solar cells," Nature Materials, vol. 12, no. 1, pp. 29-33, 2013.

[42] H. Ohkita, S. Cook, Y. Astuti et al., "Charge carrier formation in polythiophene/fullerene blend films studied by transient absorption spectroscopy," Journal of the American Chemical Society, vol. 130, no. 10, pp. 3030-3042, 2008.

[43] T. Virgili, D. Marinotto, C. Manzoni, G. Cerullo, and G. Lanzani, "Ultrafast intrachain photoexcitation of polymeric semiconductors," Physical Review Letters, vol. 94, no. 11, Article ID 117402, 2005.

[44] J. Lee, K. Vandewal, S. R. Yost et al., "Charge transfer state versus hot exciton dissociation in polymer-fullerene blended solar cells," Journal of the American Chemical Society, vol. 132, no. 34, pp. 11878-11880, 2010.

[45] K. Vandewal, S. Albrecht, E. T. Hoke et al., "Efficient charge generation by relaxed charge-transfer states at organic interfaces," Nature Materials, vol. 13, no. 1, pp. 63-68, 2014.

[46] K. Yonezawa, M. Ito, H. Kamioka, T. Yasuda, L. Han, and Y. Moritomo, "Carrier formation dynamics of organic photovoltaics as investigated by time-resolved spectroscopy," Advances in Optical Technologies, vol. 2012, Article ID 316045, 10 pages, 2012.

[47] G. Grancini, D. Polli, D. Fazzi, J. Cabanillas-Gonzalez, G. Cerullo, and G. Lanzani, "Transient absorption imaging of P3HT:PCBM photovoltaic blend: evidence for interfacial charge transfer state," Journal of Physical Chemistry Letters, vol. 2, no. 9, pp. 1099-1105, 2011.

[48] S. Trotzky, T. Hoyer, W. Tuszynski, C. Lienau, and J. Parisi, "Femtosecond up-conversion technique for probing the charge transfer in a P3HT:PCBM blend via photoluminescence quenching," Journal of Physics D: Applied Physics, vol. 42, no. 5, Article ID 055105, 2009.

[49] J. Piris, T. E. Dykstra, A. A. Bakulin et al., "Photogeneration and ultrafast dynamics of excitons and charges in P3HT/PCBM blends," Journal of Physical Chemistry C, vol. 113, no. 32, pp. 14500-14506, 2009.
[50] S. Cook, R. Katoh, and A. Furube, "Ultrafast studies of charge generation in PCBM:P3HT blend films following excitation of the fullerene PCBM," The Journal of Physical Chemistry C, vol. 113, no. 6, pp. 2547-2552, 2009.

[51] S. Cook, A. Furube, and R. Katoh, "Analysis of the excited states of regioregular polythiophene P3HT," Energy \& Environmental Science, vol. 1, no. 2, pp. 294-299, 2008.

[52] J. M. Szarko, J. Guo, B. S. Rolczynski, and L. X. Chen, "Current trends in the optimization of low band gap polymers in bulk heterojunction photovoltaic devices," Journal of Materials Chemistry, vol. 21, no. 22, pp. 7849-7857, 2011.

[53] B. S. Rolczynski, J. M. Szarko, H. J. Son, Y. Liang, L. Yu, and L. $\mathrm{X}$. Chen, "Ultrafast intramolecular exciton splitting dynamics in isolated low-band-gap polymers and their implications in photovoltaic materials design," Journal of the American Chemical Society, vol. 134, no. 9, pp. 4142-4152, 2012.

[54] K. Yonezawa, H. Kamioka, T. Yasuda, L. Han, and Y. Moritomo, "Exciton-to-carrier conversion processes in a low-band-gap organic photovoltaic," Japanese Journal of Applied Physics, vol. 52, no. 6, Article ID 062405, 2013.

[55] K. Yonezawa, H. Kamioka, T. Yasuda, L. Han, and Y. Moritomo, "Robust carrier formation process in low-band gap organic photovoltaics," Applied Physics Letters, vol. 103, no. 17, Article ID 173901, 2013.

[56] T. Akaba, K. Yonezawa, H. Kamioka, T. Yasuda, L. Han, and Y. Moritomo, "Carrier formation dynamics of a small-molecular organic photovoltaic," Applied Physics Letters, vol. 102, no. 13, Article ID 133901, 2013.

[57] K. Yonezawa, H. Kamioka, T. Yasuda, L. Han, and Y. Moritomo, "Fast carrier formation from acceptor exciton in low-gap organic photovotalic," Applied Physics Express, vol. 5, no. 4, Article ID 42302, 2012.

[58] J. Guo, Y. Liang, J. Szarko et al., "Structure, dynamics, and power conversion efficiency correlations in a new low bandgap polymer: PCBM solar cell," Journal of Physical Chemistry B, vol. 114, no. 2, pp. 742-748, 2010.

[59] K. Yonezawa, T. Yasuda, and Y. Moritomo, “Temperature effects on carrier formation dynamics in organic heterojunction solar cell," Applied Physics Letters, vol. 107, no. 13, Article ID 133903, 2015.

[60] K. Yonezawa, T. Yasuda, and Y. Moritomo, "Temperatureindependent carrier formation dynamics in bulk heterojunction," Applied Physics Express, vol. 8, no. 11, Article ID 112301, 2015.

[61] Y. Moritomo, K. Yonezawa, and T. Yasuda, "Effect of temperature on carrier formation efficiency in organic photovoltaic cells," Applied Physics Letters, vol. 105, no. 7, Article ID 073902, 2014.

[62] Y. Kanai and J. C. Grossman, "Insights on interfacial charge transfer across $\mathrm{P} 3 \mathrm{HT} /$ fullerene photovoltaic heterojunction from ab initio calculations," Nano Letters, vol. 7, no. 7, pp. 19671972, 2007.

[63] S. D. Dimitrov, A. A. Bakulin, C. B. Nielsen et al., "On the energetic dependence of charge separation in low-band-gap polymer/fullerene blends," Journal of the American Chemical Society, vol. 134, no. 44, pp. 18189-18192, 2012.

[64] H. Tamura, I. Burghardt, and M. Tsukada, "Exciton dissociation at thiophene/fullerene interfaces: the electronic structures and quantum dynamics," Journal of Physical Chemistry C, vol. 115, no. 20, pp. 10205-10210, 2011.

[65] H. Tamura and I. Burghardt, "Ultrafast charge separation in organic photovoltaics enhanced by charge delocalization and 
vibronically hot exciton dissociation," Journal of the American Chemical Society, vol. 135, no. 44, pp. 16364-16367, 2013.

[66] M. Huix-Rotllant, H. Tamura, and I. Burghardt, "Concurrent effects of delocalization and internal conversion tune charge separation at regioregular polythiophene-fullerene heterojunctions," The Journal of Physical Chemistry Letters, vol. 6, no. 9, pp. 1702-1708, 2015.

[67] H. Iizuka and T. Nakayama, "Quantum process of exciton dissociation at organic semiconductor interfaces: effects of interface roughness and hot exciton," Japanese Journal of Applied Physics, vol. 55, no. 2, Article ID 021601, 2016.

[68] R. A. Marcus, "Electron transfer reactions in chemistry. Theory and experiment," Reviews of Modern Physics, vol. 65, no. 3, pp. 599-610, 1993.

[69] M. T. Dang, L. Hirsch, and G. Wantz, "P3HT:PCBM, best seller in polymer photovoltaic research," Advanced Materials, vol. 23, no. 31, pp. 3597-3602, 2011.

[70] M. T. Dang, L. Hirsch, G. Wantz, and J. D. Wuest, "Controlling the morphology and performance of bulk heterojunctions in solar cells. Lessons learned from the benchmark poly(3hexylthiophene): [6,6]-phenyl- $\mathrm{C}_{61}$-butyric acid methyl ester system," Chemical Reviews, vol. 113, no. 5, pp. 3734-3765, 2013.

[71] G. Dennler, M. C. Scharber, and C. J. Brabec, "Polymer-fullerene bulk-heterojunction solar cells," Advanced Materials, vol. 21, no. 13, pp. 1323-1338, 2009.

[72] J. S. Moon, J. K. Lee, S. Cho, J. Byun, and A. J. Heeger, "Columnlike' structure of the cross-sectional morphology of bulk heterojunction materials," Nano Letters, vol. 9, no. 1, pp. 230-234, 2009.

[73] Y. Liang, Y. Wu, D. Feng et al., "Development of new semiconducting polymers for high performance solar cells," Journal of the American Chemical Society, vol. 131, no. 1, pp. 56-57, 2009.

[74] Y. Liang and L. Yu, "A new class of semiconducting polymers for bulk heterojunction solar cells with exceptionally high performance," Accounts of Chemical Research, vol. 43, no. 9, pp. 1227-1236, 2010.

[75] Z. He, C. Zhong, S. Su, M. Xu, H. Wu, and Y. Cao, "Enhanced power-conversion efficiency in polymer solar cells using an inverted device structure," Nature Photonics, vol. 6, no. 9, pp. 591-595, 2012.

[76] G. J. Hedley, A. J. Ward, A. Alekseev et al., "Determining the optimum morphology in high-performance polymer-fullerene organic photovoltaic cells," Nature Communications, vol. 4, article 2867, 2013.

[77] B. A. Collins, Z. Li, J. R. Tumbleston, E. Gann, C. R. McNeill, and H. Ade, "Absolute measurement of domain composition and nanoscale size distribution explains performance in PTB7:PC ${ }_{71}$ BM solar cells," Advanced Energy Materials, vol. 3, no. 1, pp. 65-74, 2013.

[78] A. Devižis, J. D. De Jonghe-Risse, R. Hany et al., "Dissociation of charge transfer states and carrier separation in bilayer organic solar cells: a time-resolved electroabsorption spectroscopy study," Journal of the American Chemical Society, vol. 137, no. 25, pp. 8192-8198, 2015.

[79] Y. Takahashi, T. Yasuda, K. Yonezawa, and Y. Moritomo, "Carrier injection dynamics in heterojunction solar cells with bipolar molecule," Applied Physics Letters, vol. 106, no. 12, Article ID 123902, 2015.

[80] Y. Moritomo, K. Yonezawa, and T. Yasuda, "Carrier density effect on recombination in PTB7-based solar cell," Scientific Reports, vol. 5, Article ID 13648, 2015.
[81] J. Kuwabara, T. Yasuda, S. J. Choi et al., "Direct arylation polycondensation: a promising method for the synthesis of highly pure, high-molecular-weight conjugated polymers needed for improving the performance of organic photovoltaics," Advanced Functional Materials, vol. 24, no. 21, pp. 3226-3233, 2014.

[82] J. Kuwabara, T. Yasuda, N. Takase, and T. Kanbara, "Effects of the terminal structure, purity, and molecular weight of an amorphous conjugated polymer on its photovoltaic characteristics," ACS Applied Materials and Interfaces, vol. 8, no. 3, pp. 1752-1758, 2016.

[83] S. Qu and H. Tian, "Diketopyrrolopyrrole (DPP)-based materials for organic photovoltaics," Chemical Communications, vol. 48, no. 25, pp. 3039-3051, 2012.

[84] A. B. Tamayo, B. Walker, and T.-Q. Nguyen, "A low band gap, solution processable oligothiophene with a diketopyrrolopyrrole core for use in organic solar cells," The Journal of Physical Chemistry C, vol. 112, no. 30, pp. 11545-11551, 2008.

[85] A. B. Tamayo, X.-D. Dang, B. Walker, J. Seo, T. Kent, and T.-Q. Nguyen, "A low band gap, solution processable oligothiophene with a dialkylated diketopyrrolopyrrole chromophore for use in bulk heterojunction solar cells," Applied Physics Letters, vol. 94, no. 10, Article ID 103301, 2009.

[86] Y. Takahashi, K. Yonezawa, H. Kamioka, T. Yasuda, L. Han, and Y. Moritomo, "Prominent charge-transfer state at $\alpha$ sexithiophene/C60 interface," Journal of the Physical Society of Japan, vol. 82, no. 6, Article ID 063709, 2013. 

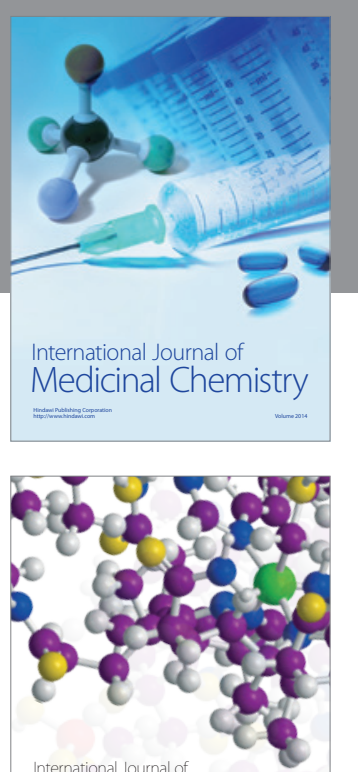

Carbohydrate Chemistry

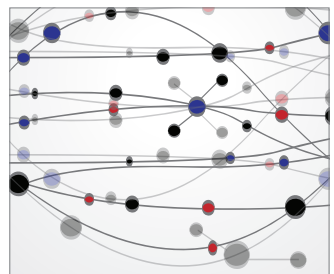

The Scientific World Journal
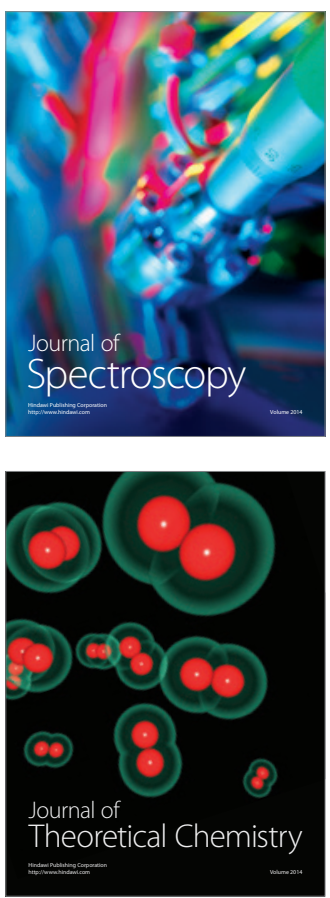
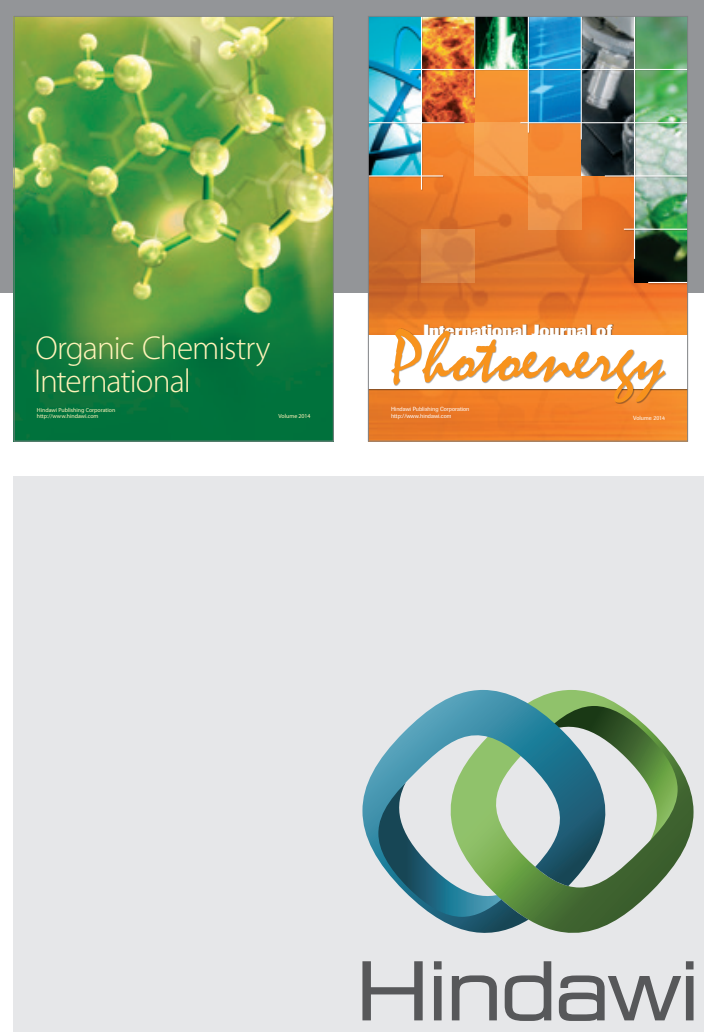

Submit your manuscripts at

http://www.hindawi.com

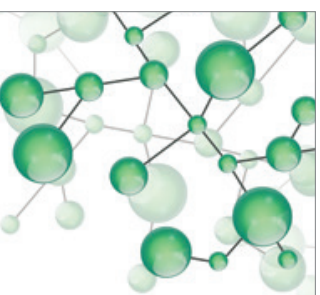

International Journal of

Inorganic Chemistry

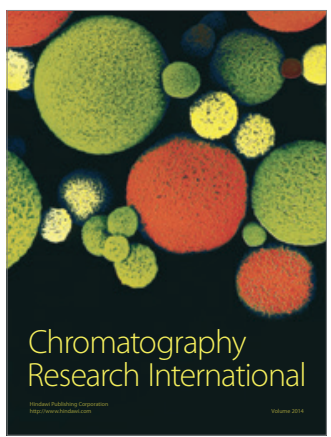

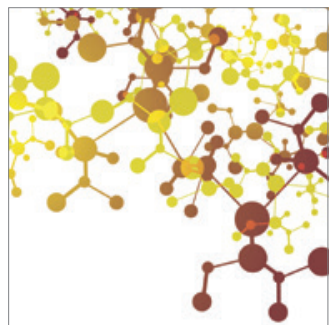

Applied Chemistry
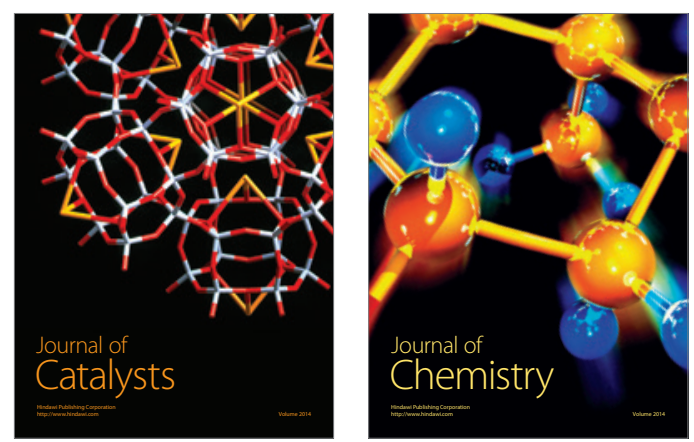
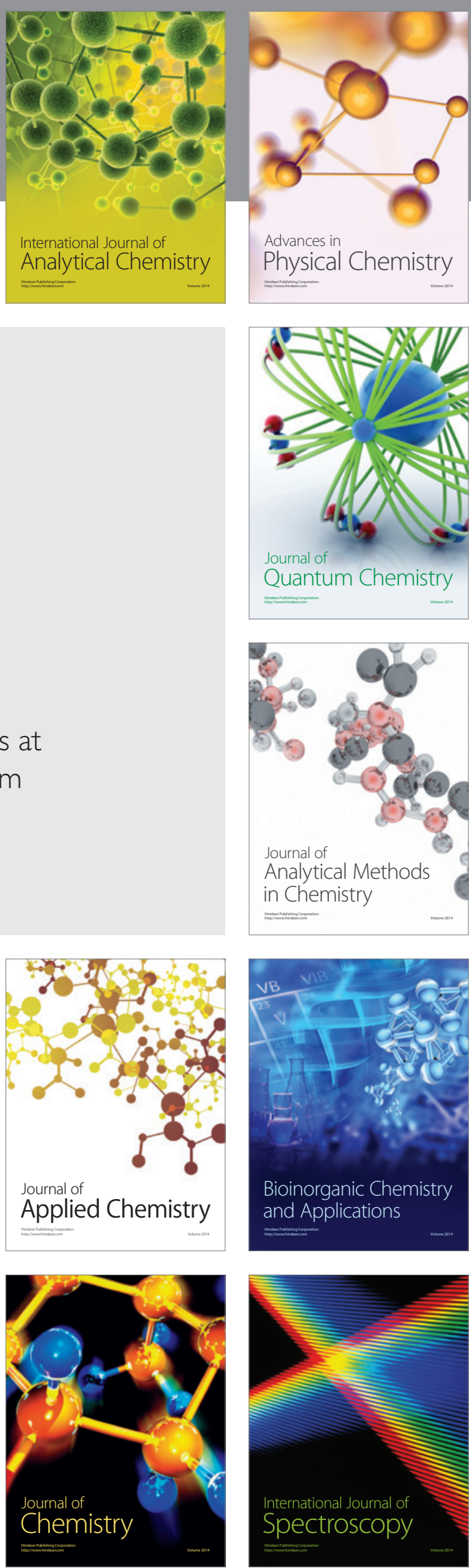